\title{
Effects of phosphorus-induced changes on the growth, nitrogen uptake, and biochemical composition of Pavlova pinguis and Hemiselmis cf. andersenii
}

\author{
Tomásia Fernandes ${ }^{1,2}$ (D) Nereida Cordeiro ${ }^{1,2}$ (D)
}

Received: 14 September 2021 / Revised: 23 November 2021 / Accepted: 23 November 2021

(c) The Author(s), under exclusive licence to Springer Nature B.V. 2021

\begin{abstract}
The understanding of the phosphorus-induced changes in the biochemical composition of microalgae is of great importance for achieving efficiency in high-value lipid production. To study the chemoplasticity of Pavlova pinguis (Haptophyceae) and Hemiselmis cf. andersenii (Cryptophyceae), their growth, carotenoid and chlorophyll $a$ content, and their monosaccharide and lipid profiles were analyzed against several phosphorus (P) regimes: low (LP), medium (MP), and high (HP). For both microalgal cultures, increasing initial $\mathrm{P}$ concentrations showed a positive effect on biomass productivities. Carbon-rich pools presented significant differences $(p<0.05)$ for $P$. pinguis against $\mathrm{P}$ treatments, in contrast to $H$. cf. andersenii. Differential responses to P-induced changes in microalgae monosaccharide and lipid profile were observed. Hemiselmis cf. andersenii increased its proportion in galactose (up to 3 times) from LP to HP conditions, whereas P. pinguis decreased (up to 20\%) its glucose proportion from LP to HP conditions. For P. pinguis, the lowest amount $\left(13.12 \mathrm{mg} \mathrm{g}^{-1} \mathrm{dw}\right)$ of sterols was observed at LP conditions, in contrast to its carotenoid content $\left(4.32 \mathrm{mg} \mathrm{g}^{-1} \mathrm{dw}\right)$. P-replete conditions were the most effective in inducing high-value lipid accumulation. Non-targeted lipid analysis revealed which samples would need to be processed to fully exploit its high-value lipids, namely $H$. cf andersenii under MP and HP conditions. This study demonstrated that P played an important role in carbon allocation, nitrogen uptake, and lipid regulation on $P$. pinguis and $H$. cf. andersenii, and that P-replete conditions could be useful for optimizing high-value lipids with potential for nutraceutical and pharmaceutical fields.
\end{abstract}

Keywords Microalga $\cdot$ Pavlova pinguis $\cdot$ Hemiselmis cf. andersenii $\cdot$ Phosphorus $\cdot$ Monosaccharides $\cdot$ High-value lipids

\section{Introduction}

Increasing concerns regarding consumer safety, environmental sustainability, and regulatory issues over synthetic materials have turned consumers' attention to natural products (Vieira et al. 2020). Microalgae are often presented as promising sustainable cell factories for their ability to convert atmospheric carbon dioxide, water, inorganic nutrients, and sunlight to high-value compounds (Fu et al. 2016). These organisms are primary producers of essential nutrients that

Nereida Cordeiro

ncordeiro@staff.uma.pt

1 LB3, Faculty of Sciences and Engineering, University of Madeira, Campus Universitário da Penteada, 9020-105 Funchal, Portugal

2 CIIMAR - Interdisciplinary Centre of Marine and Environmental Research, University of Porto, 4450-208 Matosinhos, Portugal perform vital functions in the human organism and whose dietary intake is mandatory (Khozin-Goldberg et al. 2011). Improvement of microalgae production often involves the application of several stress-inducement strategies from which nutrient stress is the most employed due to its low cost and easy applicability at both lab and large-scale cultivation (Singh et al. 2016).

Phosphorus (P) plays a significant role in algal growth and cell division due to its role as an essential component of nucleic acids, phospholipids, and phosphorylated sugars (Roopnarain et al. 2014). Besides algal growth, $\mathrm{P}$ is involved in metabolic processes like signal transduction, photosynthesis, and energy transfer (in the form of adenosine triphosphate (ATP) and nicotinamide adenine dinucleotide phosphate $\left(\mathrm{NADP}^{+}\right)$(Roopnarain et al. 2014; Yaakob et al. 2021). Due to its fast recycling, P limitation has been observed in microalgae natural environments (Alipanah et al. 2018). Microalgal $P$ requirements are known to vary considerably between species ranging from 0.001 to 
$0.179 \mathrm{~g} \mathrm{~L}^{-1}$ (Roopnarain et al. 2014). This macronutrient can be uptaken by microalgae in the form of orthophosphate (most commonly used; $\mathrm{PO}_{4}^{3-}$ ) and polyphosphate (Alipanah et al. 2018; Yaakob et al. 2021). Moreover, in $\mathrm{P}$-replete conditions, algae can store excess $\mathrm{P}$ in polyphosphate bodies (luxury uptake) (Grobbelaar 2013).

To cope with $\mathrm{P}$ limitation, microalgae modulate several metabolic pathways affecting their biomass composition (Alipanah et al. 2018). From the main macromolecular pools, lipids and carbohydrates are especially affected by internal and external P supplies (Grobbelaar 2013). According to Markou et al. (2012), carbohydrate accumulation due to P-starvation is reported to occur in diatoms, green algae, and cyanobacteria. Nevertheless, a different response was reported to occur in the Haptophyta Isochrysis galbana in which P-starvation stimulated lipid accumulation by up to $50 \%$ (Yaakob et al. 2021).

Phytosterols, polyunsaturated fatty acids (PUFA), and lipid-soluble compounds, like carotenoids and tocopherols, are important for a variety of nutraceutical and pharmaceutical purposes, and their market is continuously growing (Vieira et al. 2020). These compounds are wellknown for their health benefits in humans including neuroprotective, anti-inflammatory, anti-cancer, and antioxidant activities as well as their action as chemoprotective agents in cardiovascular diseases (Luo et al. 2015; Mudimu et al. 2017; Harwood 2019). Most studies evaluating the effects of $\mathrm{P}$ stress on microalgae have focused on the changes of specific classes of lipid families such as fatty acids and sterols (Piepho et al. 2010, 2012). Nonetheless, a non-targeted lipophilic characterization was applied by Fernandes et al. (2021) focusing on nitrogen-induced changes instead of phosphorus.

Although its wide taxonomic diversity and metabolic differences, studies on the effect of $\mathrm{P}$ on microalgal lipid profile have been limited to few species most of them belonging to the Chlorophyta phylum (Cañavate et al. 2017). In previous studies, the haptophyte Pavlova pinguis (Fernandes et al. 2020) and the cryptophyte $H$. cf. andersenii (Fernandes and Cordeiro 2020; Fernandes et al. 2021) have demonstrated to be promising candidates for highvalue lipid production. However, the mechanisms that led to carbon allocation and lipid remodeling in response to environmental-induced perturbations are poorly explored for these two microalgae. Therefore, to increase knowledge on the chemoplasticity (ability of microalgae to change its chemical composition in response to extrinsic stimuli by reorganizing its metabolome) of $P$. pinguis and $H$. cf. andersenii, their carotenoid and chlorophyll $a$ content, and monosaccharide and lipid profiles were analyzed against several phosphorus regimes.

\section{Material and methods}

\section{Growth and culture conditions}

The marine haptophyte Pavlova pinguis (RCC 1539) was obtained from the Roscoff Culture Collection (RCC), whereas the marine cryptophyte Hemiselmis cf. andersenii (BEA 0118B) was obtained from the Spanish Bank of Algae (BEA). The microalgal cultures were started with a 1:10 inoculum from exponentially growing cultures into $1 \mathrm{~L}$ of media as in Sun et al. (2018), with initial cell concentrations of $0.54 \times 10^{6}$ cells $\mathrm{mL}^{-1}$ for $H$. cf. andersenii, and $1.29 \times 10^{6}$ cells $\mathrm{mL}^{-1}$ for $P$. pinguis. Microalgal cell cultures were grown on $1 \mathrm{~L}$ of sterile medium with $\mathrm{pH}$ adjusted to 7.0 under $70 \mu \mathrm{mol}$ photons $\mathrm{m}^{-2} \mathrm{~s}^{-1}$, light intensity with $16: 8 \mathrm{~h}$ (light:dark cycles) at $25^{\circ} \mathrm{C}$ as in Fernandes et al. (2020). For the phosphorus-induced changes, f/2-Si medium (Guillard and Ryther 1962; Guillard 1975) was used as the basal formula (Table 1), and compressed air $\left(100 \mathrm{~mL} \mathrm{~min}{ }^{-1}\right)$ was used for aeration of cell cultures and as a carbon source. The different phosphorus regimes were performed by adjusting sodium dihydrogen phosphate monohydrate $\left(\mathrm{NaH}_{2} \mathrm{PO}_{4} \cdot \mathrm{H}_{2} \mathrm{O}\right)$ concentrations to $3.62 \mu \mathrm{M}$ (low phosphorus; LP), $36.20 \mu \mathrm{M}$ (medium phosphorus; MP), and $72.40 \mu \mathrm{M}$ (high phosphorus; HP). The N:P molar ratios for LP, MP, and HP treatments were 244:1, 24:1, and 12:1, respectively. The LP concentration was chosen to trigger a reduced phosphorus supply close to phosphorus depletion without compromising biomass

Table 1 Culture medium composition of f/2-Si medium (Guillard and Ryther 1962; Guillard 1975)

\begin{tabular}{ll}
\hline Component & $\begin{array}{l}\text { Concentration in } \\
\text { final medium }(m o l \\
\left.\mathrm{L}^{-1}\right)\end{array}$ \\
\hline $\mathrm{NaNO}_{3}$ & $8.82 \times 10^{-4}$ \\
$\mathrm{NaH}_{2} \mathrm{PO}_{4} \cdot \mathrm{H}_{2} \mathrm{O}$ & Variable* \\
$\mathrm{Na}_{2} \mathrm{SiO}_{3}$ & $1.06 \times 10^{-4}$ \\
$\mathrm{FeCl}_{3} \cdot 6 \mathrm{H}_{2} \mathrm{O}$ & $1.17 \times 10^{-5}$ \\
$\mathrm{Na}_{2} \mathrm{EDTA}^{2} 2 \mathrm{H}_{2} \mathrm{O}$ & $1.17 \times 10^{-5}$ \\
$\mathrm{MnCl}_{2} \cdot 4 \mathrm{H}_{2} \mathrm{O}$ & $9.10 \times 10^{-7}$ \\
$\mathrm{ZnSO}_{4} \cdot 7 \mathrm{H}_{2} \mathrm{O}$ & $7.65 \times 10^{-8}$ \\
$\mathrm{CoCl}_{2} \cdot 6 \mathrm{H}_{2} \mathrm{O}$ & $4.20 \times 10^{-8}$ \\
$\mathrm{CuSO}_{4} \cdot 5 \mathrm{H}_{2} \mathrm{O}$ & $3.93 \times 10^{-8}$ \\
$\mathrm{Na}_{2} \mathrm{MoO}_{4} \cdot 2 \mathrm{H}_{2} \mathrm{O}$ & $2.60 \times 10^{-8}$ \\
$\mathrm{Thiamine}$ hydrochloride & $2.96 \times 10^{-7}$ \\
$\mathrm{Biotin}_{\mathrm{Cyanocobalamin}}$ & $2.05 \times 10^{-9}$ \\
\hline
\end{tabular}

${ }^{*} \mathrm{NaH}_{2} \mathrm{PO}_{4} \cdot \mathrm{H}_{2} \mathrm{O}$ concentration in final medium was adjusted to $3.62 \mu \mathrm{M}, 36.60 \mu \mathrm{M}$, and $72.40 \mu \mathrm{M}$ for low, medium, and high phosphorus growth media, respectively 
production. The HP level was chosen to study the effects of excess phosphorus in a tolerable supplementation in microalgae. At the end of the early stationary phase, microalgae were harvested by centrifugation for $7 \mathrm{~min}$. at $3720 \times g$ and the pellets washed twice with a $0.09 \mathrm{~g} \mathrm{~L}^{-1}$ $\mathrm{NaCl}$ solution. As in Fernandes et al. (2021), the harvest days were determined as those on which the cell concentration was similar for 2 to 3 consecutive counting days, supported by non-significant differences $(p>0.05)$. Algal growth was monitored daily by measuring the optical density of the microalgal culture at $550 \mathrm{~nm}$ with an ultraviolet/ visible spectrophotometer (UV-6300PC, VWR, China). A calibration curve $\left(R^{2}=0.999, P\right.$. pinguis; $R^{2}=0.993, H$. cf. andersenii) plotting cell concentration (cells $\mathrm{mL}^{-1}$ ) against absorbance was used to determine cell growth. The calibration curve was formed under normal conditions, MP conditions (equivalent to the initial $\mathrm{P}$ concentrations in $\mathrm{f} / 2$-Si growth medium). The cell concentration was estimated by counting cells with a $0.1 \mathrm{~mm}$ deep improved Neubauer hemocytometer (Marienfield Superior) in a light microscope (Olympus BX41). This method can bring some inaccuracies specifically when cell morphology, shape, size, and content of scattering substances change (Becker 1994; Lee et al. 2013). To minimize these sources of error, the wavelength of $550 \mathrm{~nm}$ is recommended by Becker (1994), namely, to avoid the range of absorption of photosynthetic pigments (Samiee-Zafarghandi et al. 2018). The logistic model of Xin et al. (2010) was used to describe the microalgal growth (Eq. (1)):

$$
X=\frac{K}{1+e^{a-r t}}
$$

where $K$ (cells $\mathrm{mL}^{-1}$ ) is the carrying capacity, $X$ (cells $\left.\mathrm{mL}^{-1}\right)$ is the cell concentration in time $t\left(\right.$ day $\left.^{-1}\right), a$ is a constant that refers to the position of the origin, and $r\left(\right.$ day $\left.^{-1}\right)$ is the specific growth rate. Fitting of the model to both microalgae raw data was performed with Solver GRG (generalized reduced gradient) nonlinear solving method in Microsoft Excel selecting $a, r$, and $K$ as decision variables.

\section{Nitrogen $\left(\mathrm{NO}_{3}^{-}-\mathrm{N}\right)$ determination}

Nitrogen $(\mathrm{N})$ was determined as nitrate $\left(\mathrm{NO}_{3}^{-}\right)$by the ultraviolet spectrophotometric screening method as reported by Wan et al. (2013). A calibration curve $\left(R^{2}=0.998\right)$ was performed using $220 \mathrm{~nm}$ optical density against nitrogen concentrations $\left(0-4.07 \mathrm{mg} \mathrm{L}^{-1}\right)$ from $\mathrm{NaNO}_{3}$ solutions. Before nitrogen determinations, liquid samples were filtered using a $0.45 \mu \mathrm{m}$ filter, diluted with deionized water, and acidified with $1 \mathrm{M} \mathrm{HCl}$. Absorbances were read with an ultraviolet/ visible spectrophotometer (UV-6300PC, VWR, China). The $\mathrm{N}$ removal (\%) was calculated as follows:
Nitrogen removal $(\%)=\left(\frac{N_{\mathrm{i}}-N_{\mathrm{f}}}{N_{\mathrm{i}}}\right) \times 100$

where $N_{\mathrm{i}}$ is the initial nitrogen concentration $\left(\mathrm{mg} \mathrm{L}^{-1}\right), N_{\mathrm{f}}$ is the final nitrogen concentration $\left(\mathrm{mg} \mathrm{L}^{-1}\right)$.

\section{Pigment determination}

Carotenoids and chlorophyll $a$ extraction and determination were performed according to Fernandes et al. (2021). For extraction, $10 \mathrm{mg}$ of microalgae dried biomass was used and $7 \mathrm{~mL}$ of a cold $80 \%$ acetone solution was added. After homogenization, the mixture was put on ultrasounds for $90 \mathrm{~min}$. Then, samples were centrifuged, supernatant transferred to pre-chilled tubes, pellets continuously washed with extraction solution, and supernatant was passed through $0.45 \mu \mathrm{m}$ filters. For chlorophyll $a$ (Chl a) and carotenoid (Car) determination through an ultraviolet-visible spectrophotometer, the following equations used by Chen and Vaidyanathan (2013) were employed:

Chl $\alpha=12.21 \mathrm{~A}_{663}-2.81 \mathrm{~A}_{646}$

$\mathrm{Car}=\frac{1000 \mathrm{~A}_{470}-3.27\left(12.21 \mathrm{~A}_{663}-2.81 \mathrm{~A}_{646}\right)-104\left(20.13 A_{646}-5.03 A_{663}\right)}{198}$

\section{Lipid profile}

\section{Lipid extraction}

Lipid extraction was performed at the end of batch cultures. Microalgal biomass lipid extraction was performed accordingly with a modified Bligh and Dyer (1959) described by Fernandes et al. (2016). In brief, to $50 \mathrm{mg}$ of dried microalgal biomass, additions of $3 \mathrm{~mL}$ of a methanol:chloroform mixture $(2: 1 ; \mathrm{v}: \mathrm{v}), 400 \mu \mathrm{L}$ of a saturated solution of potassium chloride $(\mathrm{KCl}), 2 \mathrm{~mL}$ of chloroform, and $2 \mathrm{~mL}$ of distilled water were performed. Then, the organic phase was removed and transferred to pre-weighted tubes, and lipids were determined by gravimetric quantification.

\section{Alkaline hydrolysis}

Alkaline hydrolysis was performed according to Santos et al. (2015). Thus, to two lipid aliquots, $0.5 \mathrm{M}$ of $\mathrm{NaOH}$ in aqueous methanol was added and left to react at $100{ }^{\circ} \mathrm{C}$ for $1 \mathrm{~h}$ in a nitrogen atmosphere. Acidification to $\mathrm{pH} 2$ was performed with $1 \mathrm{M} \mathrm{HCl}$, and the hydrolysis products were further extracted with dichloromethane. 


\section{Trimethylsilyl derivatization and GC-MS analysis}

Before gas chromatography-mass spectrometry (GC-MS) analysis, lipid aliquots before and after alkaline hydrolysis were derivatized to trimethylsilyl (TMS) ethers and/or esters according to Santos et al. (2015). Following the addition of tetracosane (internal standard) to the lipid extracts before and after alkaline hydrolysis, additions of $250 \mu \mathrm{L}$ of pyridine, $250 \mu \mathrm{L}$ of N,O-bis(trimethylsilyl)trifluoroacetamide, and $50 \mu \mathrm{L}$ of trimethylchlorosilane were performed. Then, samples were incubated at $70{ }^{\circ} \mathrm{C}$ for $30 \mathrm{~min}$.

GC-MS analysis was performed using a gas chromatographer (6890 N, Agilent Technologies, China) equipped with a mass selective detector (5973Network, Agilent Technologies, USA) and a ValcoBond capillary column from VICI Valco $(30 \mathrm{~m} \times 0.25 \mathrm{~mm}$ inner diameter, $0.25 \mu \mathrm{m}$ film thickness) using the conditions described by Fernandes et al. (2020). The TMS derivatives were identified by comparing the retention times and mass spectra fragmentation with those obtained through injection of the standards and literature. Semi-quantitative analysis was made through the calculated response factor of each standard towards the internal standard (tetracosane). The standards used were mannose, trans-ferulic acid, nonadecan-1-ol, eicosan-1-ol, $5 \alpha$-chlolestane, cholesterol, stigmasterol, and hexadecenoic and nonadecanoic acids. Four replicates were performed for each GC-MS analysis with the results being presented as the mean value \pm standard deviation (SD) expressed in milligrams per gram of dry biomass weight (dw).

\section{Monosaccharide profile}

\section{Monosaccharide reduction and derivatization}

For monosaccharide analysis, two-stage acidic hydrolysis followed by monosaccharide reduction and acetylation was performed according to modified Blakeney et al. (1983) and described by Fernandes et al. (2017). Briefly, to $10 \mathrm{mg}$ of sample, $400 \mu \mathrm{L}$ of $72 \%$ sulfuric acid was added and left for $3 \mathrm{~h}$ at $20^{\circ} \mathrm{C}$. Next, water was added, and mixtures placed at $100{ }^{\circ} \mathrm{C}$ for $2.5 \mathrm{~h}$. At the end of acidic hydrolysis, the internal standard (myo-inositol) was added to the hydrolysate. The reduction of monosaccharides to alditols was performed to $1 \mathrm{~mL}$ of hydrolysate by addition of $200 \mu \mathrm{L}$ of a solution of $25 \%$ ammoniac $\left(\mathrm{NH}_{3}\right)$ solution and $100 \mu \mathrm{L}$ of $3 \mathrm{M} \mathrm{NH}_{3}$ containing $150 \mathrm{mg} \mathrm{mL}^{-1}$ of sodium borohydride. The mixtures were incubated at $30{ }^{\circ} \mathrm{C}$ for $1 \mathrm{~h}$, and $50 \mu \mathrm{L}$ of glacial acetic acid was added twice to the samples with homogenization in between. Alditol acetylation was performed by adding $450 \mu \mathrm{L}$ of 1-methylimidazole and $3 \mathrm{~mL}$ of acetic anhydride to $300 \mu \mathrm{L}$ of the previous mixture. Then, the solution was incubated at $30^{\circ} \mathrm{C}$ for $30 \mathrm{~min}$. Following water addition $(3.75 \mathrm{~mL})$, alditol acetates were extracted with dichloromethane $(2.5 \mathrm{~mL})$ and further washed three times with water.

\section{GC-MS analysis}

Monosaccharides were analyzed as alditol acetates by gas chromatography (Agilent HP 6890) mass spectrometry (Agilent 5973Network) and a capillary column (DB-225 J \& W; $30 \mathrm{~m} \times 0.25 \mathrm{~mm}$ inner diameter, $0.15-\mu \mathrm{m}$ film thickness) from Agilent. After optimization, the GC-MS conditions were as follows: the inlet temperature was $220^{\circ} \mathrm{C}$ and initial column temperature was $210^{\circ} \mathrm{C}$ for $3 \mathrm{~min}$. Then, the column temperature increased at a rate of $1{ }^{\circ} \mathrm{C} \mathrm{min}^{-1}$ until reaching $220{ }^{\circ} \mathrm{C}$ and $10{ }^{\circ} \mathrm{C} \mathrm{min}^{-1}$ until $230^{\circ} \mathrm{C}$ which was kept for $2 \mathrm{~min}$. The transfer line temperature was $240{ }^{\circ} \mathrm{C}$, the split ratio was 50:1, and helium was used as the carrier gas with a ramped flow rate of $1.0 \mathrm{~mL} \mathrm{~min}{ }^{-1}$ for 6 min increasing to $1.2 \mathrm{~mL} \mathrm{~min}^{-1}$ and remaining constant until the end of the run. The derivatized monosaccharides were identified by comparing the retention times and mass spectra fragmentation with those obtained through injection of the standards. The monosaccharide quantification was made through the calculated response factor of each standard towards the internal standard (myo-inositol). The standards used were myo-inositol, $\mathrm{L}(+)$ arabinose, $\mathrm{D}(+)$ xylose, $\mathrm{D}(+)$ galactose, $\mathrm{D}(+)$ glucose, $\mathrm{D}(+)$ mannose, monohydrate $\mathrm{D}(+)$ rhamnose, and $\mathrm{D}(+)$ fucose purchased at Sigma-Aldrich (USA). Four replicates were performed for each GC-MS analysis with the results being presented as the mean value \pm SD of monosaccharides expressed in $\mathrm{mg} \mathrm{g}^{-1} \mathrm{dw}$.

\section{Statistical analysis}

Analysis of variance (ANOVA) followed by Tukey post hoc analysis was performed using IBM SPSS Statistics 26 software, $p$ values $<0.05$ were considered statistically significant, whereas for principal component analysis (PCA), Pearson correlation, and hierarchical clustering heat maps, the Metaboanalyst 5.0 webserver (Pang et al. 2021) was used. Before PCA, Pearson correlation, and hierarchical clustering heat maps, features were median normalized, $\log _{2}$ transformed, and auto scaled. For hierarchical clustering heat maps, Euclidean clustering distance and ward clustering method were used.

\section{Results and discussion}

\section{Microalgal growth and chemical composition}

Phosphorus is an essential nutrient for the growth and division of microalgal cells (Roopnarain et al. 2014). Growth dynamics of Hemiselmis cf. andersenii (Fig. 1a) and Pavlova 
Fig. 1 Growth curves obtained for Hemiselmis cf. andersenii (a) and Pavlova pinguis (b) under low (LP), medium (MP), and high (HP) starting phosphorus concentrations. Values are expressed as mean \pm standard deviation, $n=3$. The determination coefficients $\left(r^{2}\right)$ for the growth models were higher than 0.90 . * Values are not significantly different $(p>0.05)$ among cultivation days, within each treatment a)

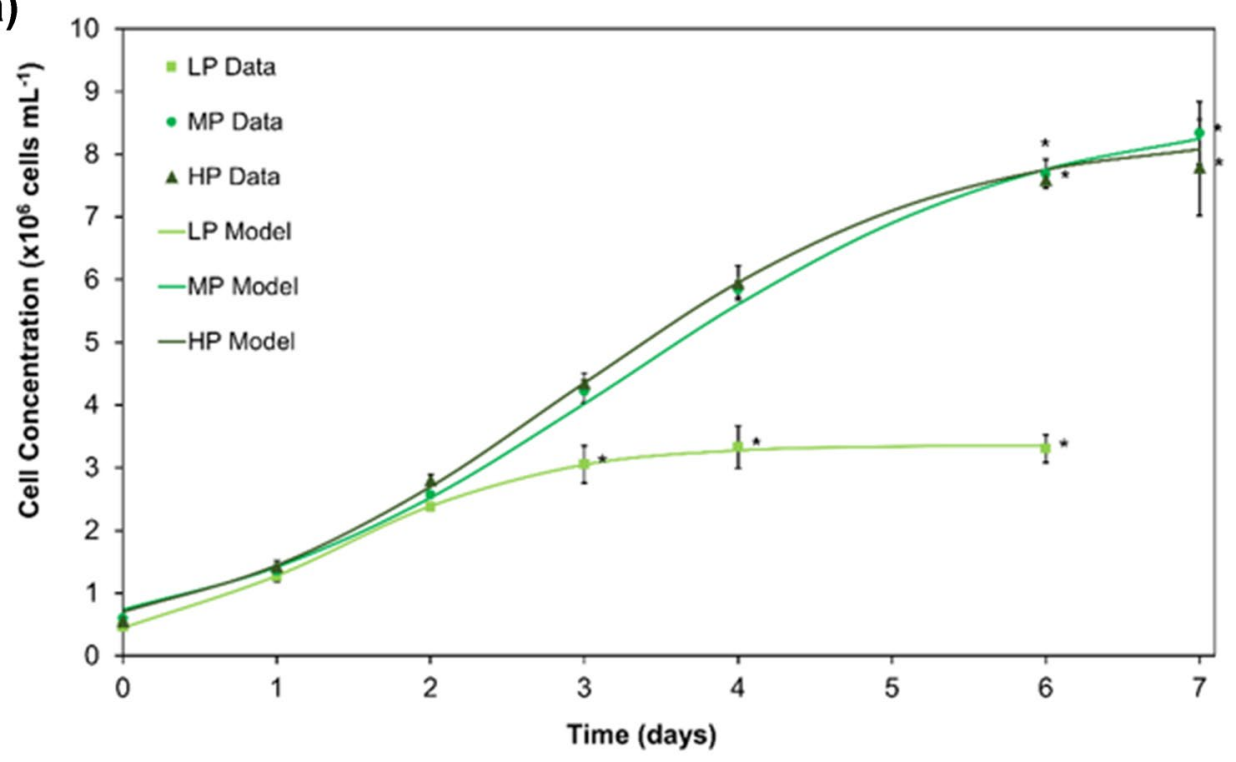

b)

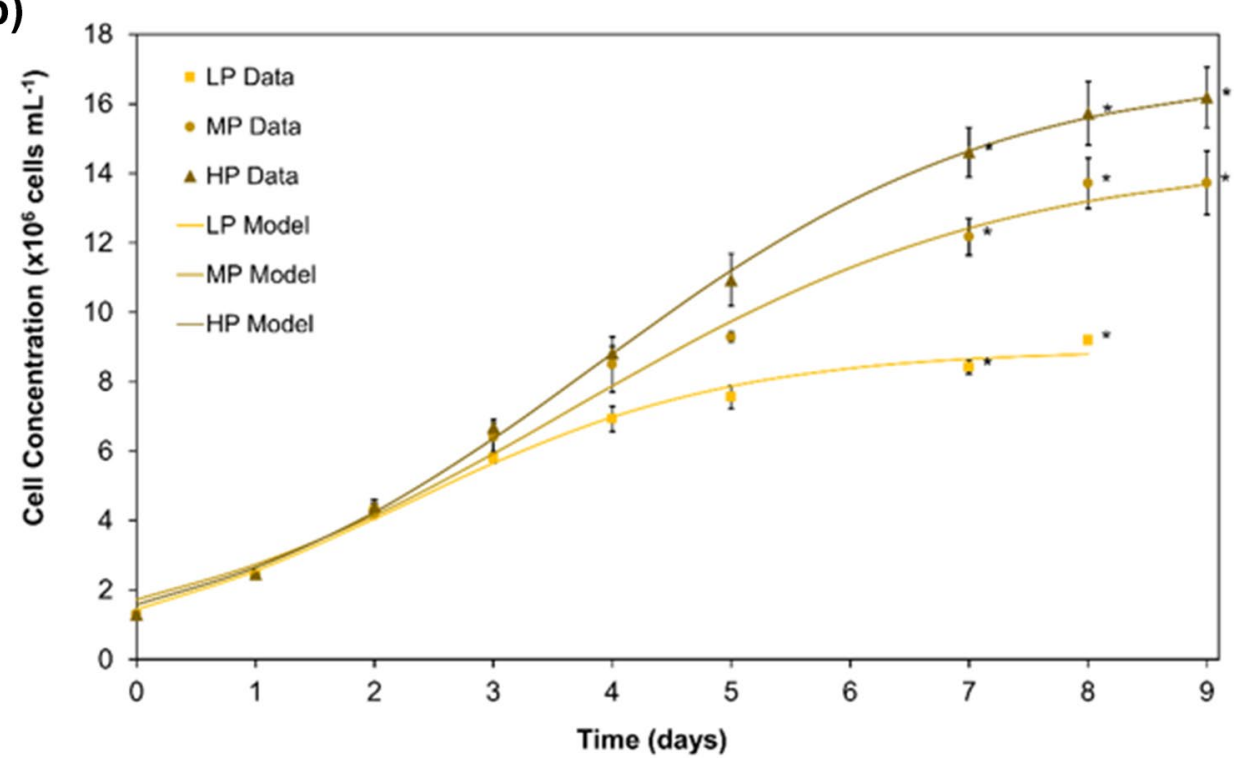

pinguis (Fig. 1b) were analyzed under different initial phosphorus regimes. In Fig. 1, it is possible to observe that microalgal growth varied with the different initial phosphorus supplies, with microalgae at LP conditions presenting lower cell harvest density (Table 2) and reaching early stationary phase more quickly than microalgae grown at MP and HP conditions. Biomass productivity determines the prospective of microalgae for efficient high-value compounds. According to Patel et al. (2012), higher P loadings are often associated with higher biomass accumulation and productivity. For $H$. cf. andersenii and $P$. pinguis cultures, significant differences $(p<0.05)$ were observed for biomass productivity across $\mathrm{P}$ treatments, with increasing phosphorus concentrations exhibiting a positive effect on biomass productivities, with the greatest values being achieved at
HP conditions 30.05 and $43.91 \mathrm{mg} \mathrm{L}^{-1}$ day $^{-1}$ respectively. These values are greater than those reported by Slocombe et al. (2015) of $13 \mathrm{mg} \mathrm{L}^{-1} \mathrm{day}^{-1}$ for another cryptophyte (Rhodomonas reticulata).

In $H$. cf. andersenii, nitrogen uptake was affected by initial phosphorus concentrations in growth media. Figure S1a shows that at day 2 the nitrogen uptake by $H$. cf. andersenii under LP conditions ceased despite only $41 \%$ of nitrogen had been removed. This indicates that a nutrient other than nitrogen has become limiting, influencing not only nitrogen acquisition but also the beginning of the stationary phase verified at day 3 of cultivation (Fig. 1a). Since this occurs in $H$. cf. andersenii cultures with a reduced initial phosphorus concentration, these results suggest that phosphorus was the limiting nutrient at these conditions, instead of nitrogen. 
Table 2 Cell harvest density, biomass productivity, nitrogen removal, lipid, and monosaccharide content of Hemiselmis cf. andersenii and Pavlova pinguis under low, medium, and high phosphorus supplementation

\begin{tabular}{|c|c|c|c|c|c|c|}
\hline & \multicolumn{3}{|c|}{ Hemiselmis cf. andersenii } & \multicolumn{3}{|l|}{ Pavlova pinguis } \\
\hline & Low & Medium & High & Low & Medium & High \\
\hline Cell harvest density $\left(\times 10^{6}\right.$ cells $\left.\mathrm{mL}-{ }^{1}\right)$ & $3.30 \pm 0.22^{\mathrm{a}}$ & $8.34 \pm 0.50^{\mathrm{b}}$ & $7.79 \pm 0.77^{\mathrm{b}}$ & $9.20 \pm 0.02^{\mathrm{A}}$ & $13.72 \pm 0.91^{\mathrm{B}}$ & $16.18 \pm 0.87^{\mathrm{B}}$ \\
\hline $\begin{array}{l}\text { Biomass productivity (mg dw } \mathrm{L}^{-1} \\
\text { day }^{-1} \text { ) }\end{array}$ & $17.52 \pm 1.36^{\mathrm{a}}$ & $26.07 \pm 4.08^{\mathrm{b}}$ & $30.05 \pm 0.03^{\mathrm{b}}$ & $33.41 \pm 0.47^{\mathrm{A}}$ & $43.10 \pm 3.47^{\mathrm{B}}$ & $43.91 \pm 3.41^{\mathrm{B}}$ \\
\hline Nitrogen removal (\%) & $41.14 \pm 0.99^{\mathrm{a}}$ & $86.79 \pm 1.42^{\mathrm{b}}$ & $87.22 \pm 1.88^{\mathrm{b}}$ & $83.28 \pm 0.02^{\mathrm{A}}$ & $84.70 \pm 1.31^{\mathrm{A}}$ & $84.16 \pm 1.33^{\mathrm{A}}$ \\
\hline Lipid (\% dw) & $12.58 \pm 0.64^{\mathrm{a}}$ & $20.46 \pm 1.09^{\mathrm{b}}$ & $17.64 \pm 2.3^{\mathrm{b}}$ & $23.23 \pm 0.93^{\mathrm{AB}}$ & $25.11 \pm 0.67^{\mathrm{A}}$ & $21.87 \pm 1.26^{\mathrm{B}}$ \\
\hline Monosaccharide $\left(\mathrm{mg} \mathrm{g}^{-1} \mathrm{dw}\right)$ & $132.16 \pm 1.21^{\mathrm{a}}$ & $240.47 \pm 0.74^{b}$ & $193.41 \pm 0.61^{\mathrm{c}}$ & $180.27 \pm 1.40^{\mathrm{A}}$ & $156.18 \pm 5.27^{\mathrm{B}}$ & $139.43 \pm 0.78^{\mathrm{C}}$ \\
\hline Rhamnose & $1.24 \pm 0.11^{\mathrm{a}}$ & $0.97 \pm 0.07^{\mathrm{b}}$ & $1.10 \pm 0.11^{\mathrm{ab}}$ & $1.16 \pm 0.10^{\mathrm{A}}$ & $1.61 \pm 0.13^{\mathrm{B}}$ & $1.12 \pm 0.21^{\mathrm{A}}$ \\
\hline Arabinose & n.d & n.d & n.d & $0.81 \pm 0.22^{\mathrm{A}}$ & $2.43 \pm 0.38^{\mathrm{B}}$ & $2.05 \pm 0.07^{\mathrm{B}}$ \\
\hline Xylose & n.d & $0.21 \pm 0.04^{\mathrm{a}}$ & $0.35 \pm 0.01^{\mathrm{b}}$ & $0.45 \pm 0.05^{\mathrm{A}}$ & $0.95 \pm 0.18^{\mathrm{B}}$ & $0.75 \pm 0.09^{\mathrm{B}}$ \\
\hline Mannose & $74.04 \pm 0.76^{\mathrm{a}}$ & $130.24 \pm 0.64^{\mathrm{b}}$ & $98.97 \pm 0.46^{\mathrm{c}}$ & $81.83 \pm 0.74^{\mathrm{A}}$ & $71.13 \pm 2.69^{\mathrm{B}}$ & $74.70 \pm 0.25^{\mathrm{C}}$ \\
\hline Galactose & $0.87 \pm 0.06^{\mathrm{a}}$ & $3.77 \pm 0.13^{\mathrm{b}}$ & $3.51 \pm 0.12^{\mathrm{c}}$ & $4.08 \pm 0.12^{\mathrm{A}}$ & $6.10 \pm 0.16^{\mathrm{B}}$ & $4.25 \pm 0.08^{\mathrm{A}}$ \\
\hline Glucose & $56.01 \pm 0.48^{\mathrm{a}}$ & $105.29 \pm 0.25^{\mathrm{b}}$ & $89.47 \pm 0.61^{\mathrm{c}}$ & $91.93 \pm 0.40^{\mathrm{A}}$ & $73.96 \pm 1.95^{\mathrm{B}}$ & $56.55 \pm 0.34^{\mathrm{C}}$ \\
\hline Lipid/monosaccharide (\%dw/\%dw) & $0.95 \pm 0.05^{\mathrm{a}}$ & $0.87 \pm 0.01^{\mathrm{a}}$ & $0.91 \pm 0.12^{\mathrm{a}}$ & $1.29 \pm 0.05^{\mathrm{A}}$ & $1.61 \pm 0.05^{\mathrm{B}}$ & $1.57 \pm 0.10^{\mathrm{B}}$ \\
\hline
\end{tabular}

Values (means \pm SD of at least three replicates) in the same row, not sharing a common superscript are significantly different $(p<0.05)$. Differences among treatments assessed by one-way ANOVA followed by Tukey post-hoc analysis are represented by superscript lowercase letters for $H$. $f$. andersenii, and by superscript uppercase letters for $P$. pinguis. dw, dry weight

Different results were obtained for $H$. cf. andersenii cultures under higher phosphorus levels where no variations $(p>0.05)$ on nitrogen removal were verified for the treatments MP and HP (Table 2).

For $P$. pinguis, no differences were found for the nitrogen removal efficiency (Table 2; Fig. S1b) among treatments. These results suggest that increasing initial phosphorus concentrations, which in turn decreases N:P ratios, has no direct effect on nitrogen uptake by $P$. pinguis. These observations reinforce the assumption that the nutrient uptake ability of microalgae depends not only on its availability, environmental conditions, and nutrient ratios but also on biological factors such as species (Grobbelaar 2013).

Carotenoids (photoprotective pigments) to chlorophyll $a$ (light-harvesting pigment) ratio ( $\mathrm{Car} / \mathrm{Chl} a)$ can serve as an indicator of carotenogenesis, and as a marker of physiological stress in microalga under poor environmental conditions (Chen et al. 2017; Alipanah et al. 2018; Jo et al. 2020). For this ratio, significant variations $(p<0.05)$ under different initial phosphorus supplies for both microalgae studied were observed (Fig. 2). For $H$. cf. andersenii, LP conditions (light green; Fig. S2a) presented low carotenoids $\left(0.61 \mathrm{mg} \mathrm{g}^{-1}\right.$ $\mathrm{dw})$, Chl $a\left(1.72 \mathrm{mg} \mathrm{g}^{-1} \mathrm{dw}\right)$, and Car/Chl $a(0.36)$ ratio values, whereas for $P$. pinguis, a carotenoid accumulation was observed through an increase of $54 \%$ from MN conditions $\left(2.81 \mathrm{mg} \mathrm{g}^{-1} \mathrm{dw}\right.$ ) to LP conditions $\left(4.32 \mathrm{mg} \mathrm{g}^{-1} \mathrm{dw}\right)$ and with the highest $\mathrm{Car} / \mathrm{Chl} a(0.77)$ ratio being observed at these conditions. The low pigments (chlorophyll $a$ and carotenoids) accumulation verified for $H$. cf. andersenii under LP conditions might be derived from the combined effect of phosphorus limitation and reduced nitrogen uptake (Table 2; Fig. S1a), affecting not only cell division but also the photosynthetic efficiency of this microalga.

Color differences were verified between the microalgae exposed to distinct initial phosphorus concentrations (Fig. S2 a-b). In the last days of cultivation, $H$. cf. andersenii LP cultures (Fig. S2a) presented a light green, whereas the same microalga at MP and HP conditions displayed a dark green. These visual changes reflect the lowest pigments amount verified at LP conditions, in contrast to $H$. cf. andersenii under MP and HP conditions. For P. pinguis (Fig. S2b), LP cultures presented a yellowish color, whereas MP and HP cultures presented a brown color. A previous study (Gorgônio et al. 2013) associated the yellowish color of a haptophyte with higher levels of carotenoids, this observation being consistent with the results obtained in this study.

Microalgae-derived carotenoids have a high market potential due to their several biological activities such as antioxidant activity, hypolipidemic, anti-inflammatory, and hypotensive (Le Goff et al. 2019). Therefore, the results obtained for carotenoids and $\mathrm{Car} / \mathrm{Chl} a$ ratio indicate that phosphorus limitation constitutes a cost-efficient strategy for carotenoid production by $P$. pinguis for high-value market. Similar behavior to $P$. pinguis was observed for other haptophytes (Isochrysis galbana) in which P-starvation initiated chlorophyll reduction and carotenoid accumulation (Roopnarain et al. 2014). The accumulation of carotenoids observed for $P$. pinguis may have been a protective mechanism against photo-oxidative stress prompted by the LP conditions (Roopnarain et al. 2014). 

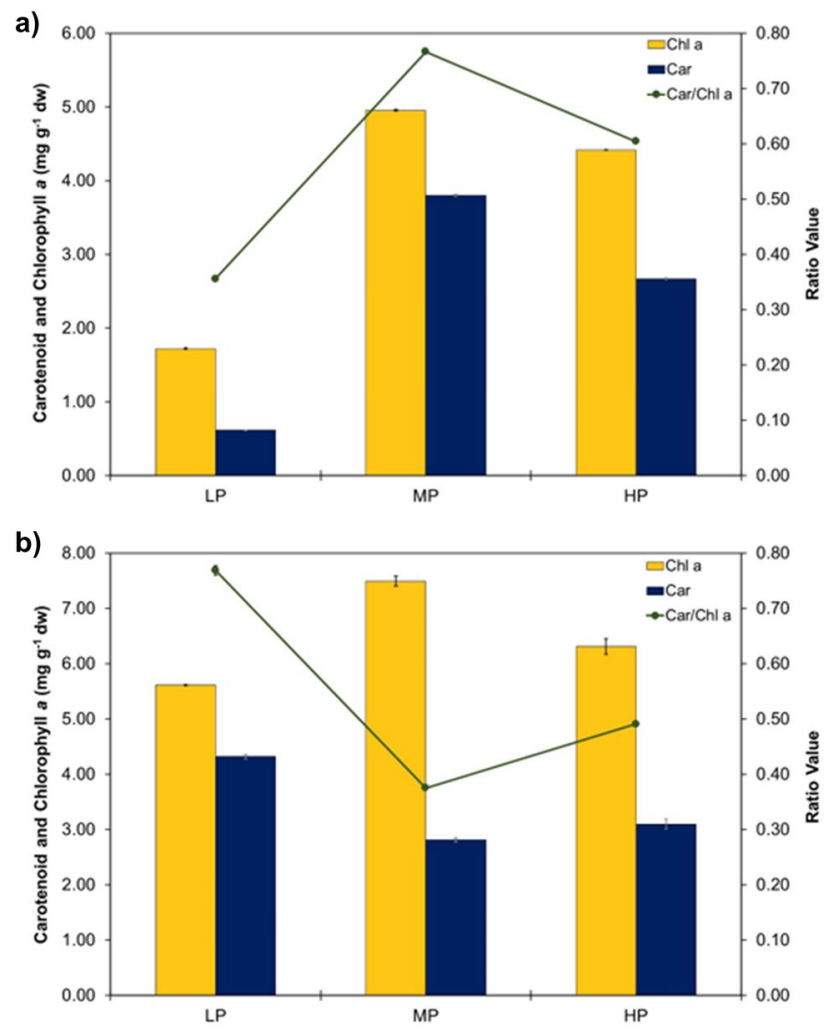

Fig. 2 Influence of different phosphorus regimes on carotenoids (Car) and chlorophyll $a(\mathrm{Chl} a)$ in Hemiselmis cf. andersenii (a) and Pavlova pinguis (b) cultures. LP, low phosphorus; MP, medium phosphorus; HP, high phosphorus supplementations. * Values are not significantly different $(p>0.05)$ among treatments

Microalgae fixed carbon can be distributed among three main macromolecular pools: protein, carbohydrate, and lipid (Yang et al. 2018). In general, microalgae use carbohydrate as their primary carbon storage pool switching their carbon partitioning towards energy-rich storage compounds like lipids under poor environmental conditions (Yang et al. 2018). However, this partition among carbon-rich pools (carbohydrate and lipid) can be species-specific (Fernandes et al. 2016). For $H$. cf. andersenii, the lipid/monosaccharide ratio remained stable across treatments with non-significant differences $(p>0.05)$ being observed for this parameter (Table 2). In this microalga, the lipid/monosaccharide ratio lower than one seems to indicate that carbohydrates are the main carbon-rich pool for this microalga. For $P$. pinguis, the lipid/monosaccharide ratio was significantly $(p<0.05)$ affected by initial phosphorus supplies reaching its lowest value (1.26) at LP conditions, suggesting that at these conditions $P$. pinguis displaced its carbon partitioning towards carbohydrate synthesis (Table 2). Moreover, an opposite trend between the $\mathrm{Car} / \mathrm{Chl} a$ ratio and the lipid/monosaccharide ratio suggests that the $\mathrm{Car} / \mathrm{Chl} a$ ratio could be a simple indicator of the carbon partitioning among lipid and carbohydrate.
A convertible relationship between carbohydrate and lipid has been reported to occur in other marine microalgae such as the haptophyte Isochrysis sp., the cryptophyte Rhodomonas marina, and the ochrophyte Nannochloropsis gaditana, as a response to environmental fluctuations (Fernandes et al. 2016, 2017). In the study performed by Fernandes et al. (2016), Isochrysis sp., which belongs to the same phylum of $P$. pinguis, also accumulated carbohydrates instead of lipid towards low nutrient conditions. However, this study targeted the change of overall nutrient availabilities, by adjusting the volume of a commercial nutrient solution, against carbon supply, which remained constant. Improvements of carbohydrate production though phosphorus limitation was reported for the cyanophyte Arthrospira platensis (Markou et al. 2012).

As shown in Table 2, P. pinguis displayed the more complex mixture of monosaccharides presenting six identified compounds: rhamnose, arabinose, xylose, mannose, galactose, and glucose. For both $H$. cf. andersenii and $P$. pinguis, glucose and mannose were the main building blocks of carbohydrate accounting for $97-98 \%$ of total monosaccharides and $93-96 \%$ of total monosaccharides, respectively. Looking at the relative abundance of monosaccharides, it is possible to observe that $H$. cf. andersenii and $P$. pinguis remodeled differently their monosaccharide composition in response to initial phosphorus inputs. Thus, $H$. cf. andersenii increased its proportions in galactose (threefold) from LP conditions towards HP conditions (Fig. 3a), whereas $P$. pinguis decreased by $20 \%$ its glucose relative abundance from LP conditions towards HP conditions (Fig. 3b). The main storage product of Haptophyta is chrysolaminaran which is a $\beta-1,3-$ glucan (Barsanti and Gualtieri 2006). Thus, the verified lowest lipid/monosaccharide ratio along with the highest monosaccharide content and glucose proportion indicates that $P$. pinguis responded to LP conditions by synthesizing this storage product.

P-starvation is often referred as an effective strategy to enhance lipid accumulation by microalgae (Satpati et al. 2016; Yang et al. 2018; Yaakob et al. 2021). Table 2 shows that lipid content was significantly $(p<0.05)$ affected by the different phosphorus regimes applied in both microalgae studied. For $H$. cf. andersenii, lipid levels ranged between 12.58 and $20.48 \% \mathrm{dw}$, and for $P$. pinguis, lipid amount varied between 21.87 and $25.11 \% \mathrm{dw}$. In both microalgae, the greatest lipid values were observed at MP conditions, while the lowest values were found at LP conditions for $H$. cf. andersenii and at HP conditions for P. pinguis. According to Saha et al. (2013), most eukaryotic microalgae proportionally accumulate lipids and carotenoids as a response to environmental stresses. In the present study, $H$. cf. andersenii showed a similar trend for both lipid and carotenoids as a response to phosphorus-induced changes.

In contrast with previous studies (Khozin-Goldberg and Cohen 2006; Satpati et al. 2016; Alipanah et al. 2018), LP conditions did not cause an increase in the lipid content in both microalgae. Additionally, $H$. cf. andersenii responded 
to LP conditions by decreasing its lipid content. The same observation was made by Reitan et al. (1994) where two (Nannochloris atomus and Tetraselmis sp.) from the seven microalgae studied responded to phosphorus limitation by decreasing its lipid content. The way by which microalgae biochemical composition is modulated in response to an external stimulus is dependent on several factors, namely species-specific differences, composition of the media, physical parameters (e.g., temperature, light intensity, $\mathrm{CO}_{2}$ aeration), and methods of cultivation (Akgül et al. 2021).

\section{Lipid remodeling}

Several studies (Cañavate et al. 2017; Alipanah et al. 2018; Murakami et al. 2018; Kokabi et al. 2019) have reported the reorganization of microalgal cellular lipids under phosphorus-induced changes. Thus, to study the impact of phosphate-induced changes on $H$. cf. andersenii and $P$. pinguis lipid composition, an untargeted approach analyzing its esterified and unesterified composition was applied. Through Tables 3 and 4, it is possible to observe that $H$. cf. andersenii and $P$. pinguis displayed different patterns of lipid remodeling as a response to phosphorus-induced changes. For all lipid sets analyzed (fatty acids, aliphatic alcohols, sterols, monoglycerides, and other compounds), significant differences $(p<0.05)$ were observed across treatments in both microalgae studied.

Fatty acids are the main lipid compounds studied when assessing the impact of phosphorus-induced changes on microalgae (Cañavate et al. 2017). Previous studies (Siron
Fig. 3 Changes in monosaccharides proportions for Hemiselmis cf. andersenii (a) and Pavlova pinguis (b) against phosphorus treatments: LP, low phosphorus; MP, medium phosphorus; HP, high phosphorus supplementations. * Values are not significantly different $(p>0.05)$ among treatments
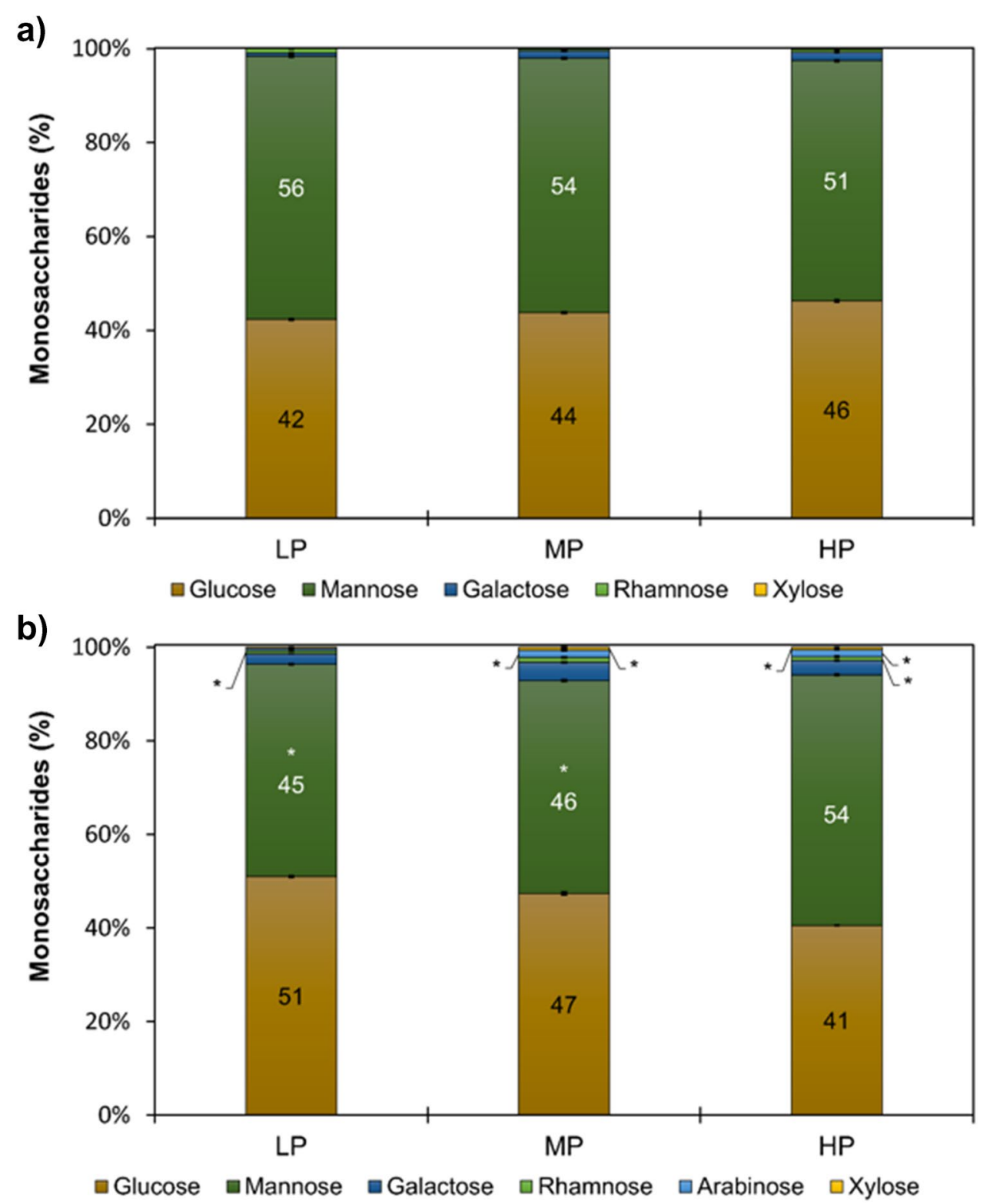
et al. 1989; Khozin-Goldberg and Cohen 2006; Cañavate et al. 2017) report that low phosphorus conditions trigger fatty acid accumulation in most microalgae. For $H$. cf. andersenii samples, total fatty acids increased by increasing initial phosphorus concentrations, which, in turn, leads to a great increase in the main fatty acids hexadecanoic

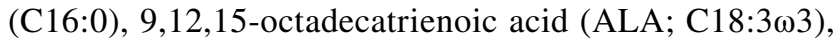
and 5,8,11,14,17-eicosapentaenoic acids (C20:5 33$)$. For $P$. pinguis, a slight decrease of $11 \%$ was verified in its total fatty acids' levels in HP samples after hydrolysis.

As building blocks of lipids, fatty acids were the most affected by alkaline hydrolysis, increasing up to $43 \%$ in $H$. cf. andersenii at HP conditions and up to $41 \%$ in $P$. pinguis at LP conditions. Within fatty acids, polyunsaturated fatty acids (PUFA) presented the highest increase after hydrolysis for $H$. cf. andersenii samples (up to $81 \%$ at HP conditions), whereas for $P$. pinguis, saturated fatty acids (SFA) presented the greatest increase (up to $46 \%$ at LP conditions). Since PUFA are often attributed to polar lipids, whereas SFA are mainly enriched in triacyclglycerols (Shen et al. 2016), this may indicate that $P$. pinguis has a richer composition in neutral lipids (triacylglycerols) than $H$. cf. andersenii.

The production of enhanced amounts of nutritionally important fatty acids by microalgae would have added value as an ingredient for various functional food, cosmetics, and nutraceutical products (Saha et al. 2013). Figure 4 shows the effect of phosphorus-induced changes on $H$. cf. andersenii (Fig. 4a) and P. pinguis (Fig. 4b) fatty acid dietary ratios before and after alkaline hydrolysis. $H$. cf. andersenii presented more variations in fatty acid dietary ratios than $P$. pinguis which seemed to be more stable. For $H$. cf. andersenii, the ratios more affected by alkaline hydrolysis were the EPA to 4,7,10,13,16,19-docosahexaenoic acid (DHA; C22 26 ) and PUFA/SFA ratios, which increased up to 45 and $69 \%$ after saponification respectively, indicating that the saponifiable fraction of this microalga is richer in EPA and PUFA. Moreover, the lowest value of PUFA/SFA ratio (BH: 0.48; AH: 0.81) observed at LP conditions shows that $H$. cf. andersenii tend to produce SFA in low phosphorus environments. This observation is consistent with a previous study performed for microalga Chlorophyta Scenedesmus, in which it was assumed that during phosphorus limitation this microalga tends to produce SFA (Yang et al. 2018). $H$. cf. andersenii also displayed the highest $\sum \omega 3 / \sum \omega 6$ ratio (BH: 6.50; AH: 6.78) showing its potential as a rich source of $\omega 3$ fatty acids.

Decreasing dietary SFA intake and replacing it with PUFA have been mentioned as the main dietary strategy for humans to benefit from PUFA preventive and protective activities against chronic inflammatory, cancer, diabetes, atherogenesis, and Alzheimer's disease (Shang et al. 2017; López et al. 2019). Since PUFA differ in their physiological functions, the balance between the $\omega 3$ and $\omega 6$ fatty acids, along with EPA and DHA, should be considered simultaneously (Shang et al. 2017). Thus, the ability of $H$. cf. andersenii to adjust its PUFA/SFA, $\sum \omega 3 / \sum \omega 6$, and EPA/DHA constitutes a great advantage for modulating its composition according to the supplementation purposes. Moreover, the study of the nutritional ratios before and after alkaline hydrolysis in both microalgae allows seeing which strategies can be better employed to fully exploit microalgae potential for PUFA production.

In both microalgae studied, the main aliphatic alcohols were hexadecanol, octadece-9-nol, and 3,7,11,15-tetramethyl-2-hexadecen-1-ol (phytol). Phytol and chlorophyll $a$ content presented a similar trend across phosphorus treatments for $H$. cf. andersenii after hydrolysis, with the greatest phytol (6.45 $\mathrm{mg} \mathrm{g}^{-1} \mathrm{dw}$ ) content being observed at MP conditions as with chlorophyll $a\left(7.49 \mathrm{mg} \mathrm{g}^{-1} \mathrm{dw}\right)$. This result agrees with a previous study performed by Fernandes et al. (2021) for this microalga where the positive relation between phytol and chlorophyll $a$ was also observed. The previous trend was not observed for $P$. pinguis possibly for having in its composition other phytol-derived products such as vitamins $\mathrm{K}$ and $\mathrm{E}$, like Chlorella stigmatophora. In $\mathrm{H}$. cf. andersenii samples, a very strong positive correlation $(>0.95)$ was found between phytol and the following fatty acids: tetradecanoic

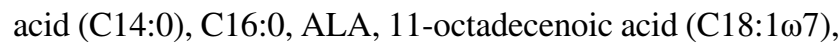
DHA, and 7,10,13,16,19-docosapentaenoic acid (C22:5 while for $P$. pinguis, a strong positive correlation $(>0.90)$ was found between phytol, EPA, and C14:0.

Sterols, carotenoids, and phytol synthesis, initiate with the biosynthesis of the isoprenoids precursors: isopentenyl pyrophosphate (IPP) and dimethylallyl pyrophosphate (DMAPP) (Sasso et al. 2012). For P. pinguis, the lowest amount (13.12 $\mathrm{mg} \mathrm{g}^{-1} \mathrm{dw}$ ) of sterols was observed at LP conditions, in contrast to its carotenoids $\left(4.32 \mathrm{mg} \mathrm{g}^{-1} \mathrm{dw}\right)$. Since phosphorus is an elemental constituent of isoprenoid precursors, the previous observation may indicate that at LP conditions $P$. pinguis promote the accumulation of carotenoids (photoprotective pigments) at the expense of sterols (membrane components). For $H$. cf. andersenii, the lowest amount $\left(1.83 \mathrm{mg} \mathrm{g}^{-1} \mathrm{dw}\right)$ of sterols was also verified at LP conditions. As with the present study, the decrease in sterol content as a response to low phosphorus environments has been reported to occur in other microalgae (Chlorophyta Scenedesmus quadricauda, and Chlamydomonas globosa, Cryptophyta Cryptomonas ovata, Bacillariophyta Cyclotella meneghiniana) (Piepho et al. 2010, 2012).

Marine microalgae have developed efficient strategies to cope with poor phosphorus environments by remodeling membrane lipids in phosphorus-free lipids (such as betaine lipid and triacylglycerols) instead of phospholipids (Cañavate et al. 2017; Murakami et al. 2018; Kokabi et al. 2019). Two metabolic pathways have been described for triacylglycerols biosynthesis: an acyl-CoA-dependent pathway 
Table 3 Lipid profile $\left(\mathrm{mg} \mathrm{g}^{-1} \mathrm{dw}\right)$ of Hemiselmis cf. andersenii and Pavlova pinguis grown in different initial phosphorus loadings before hydrolysis

\begin{tabular}{|c|c|c|c|c|c|c|c|}
\hline \multirow[t]{2}{*}{ No } & \multirow[t]{2}{*}{ Identified compounds } & \multicolumn{3}{|c|}{ Hemiselmis cf. andersenii } & \multicolumn{3}{|c|}{ Pavlova pinguis } \\
\hline & & Low & Medium & High & Low & Medium & High \\
\hline & Fatty acids & $33.51 \pm 0.92^{a}$ & $56.58 \pm 0.85^{b}$ & $50.72 \pm 0.36^{c}$ & $94.35 \pm 3.44^{A}$ & $102.96 \pm 1.45^{B}$ & $101.78 \pm 1.55^{B}$ \\
\hline & Saturated fatty acids & $18.06 \pm 0.54^{a}$ & $28.12 \pm 0.36^{b}$ & $25.63 \pm 0.22^{c}$ & $40.72 \pm 1.51^{A}$ & $43.27 \pm 0.42^{B}$ & $43.26 \pm 1.40^{B}$ \\
\hline 1 & Nonanoic acid & $1.04 \pm 0.01^{\mathrm{a}}$ & $1.57 \pm 0.00^{\mathrm{b}}$ & $1.55 \pm 0.01^{\mathrm{c}}$ & $1.53 \pm 0.01^{\mathrm{AB}}$ & $1.55 \pm 0.01^{\mathrm{A}}$ & $1.53 \pm 0.00^{\mathrm{B}}$ \\
\hline 3 & Decanoic acid & n.d & n.d & n.d & $1.54 \pm 0.01^{\mathrm{A}}$ & n.d & $1.55 \pm 0.01^{\mathrm{B}}$ \\
\hline 6 & Undecanoic acid & n.d & n.d & n.d & $1.53 \pm 0.01^{\mathrm{A}}$ & $1.54 \pm 0.02^{\mathrm{A}}$ & $1.54 \pm 0.01^{\mathrm{A}}$ \\
\hline 8 & Dodecanoic acid & n.d & n.d & n.d & $1.54 \pm 0.01^{\mathrm{A}}$ & $1.56 \pm 0.02^{\mathrm{A}}$ & $1.55 \pm 0.00^{\mathrm{A}}$ \\
\hline 12 & Tetradecanoic acid & $1.12 \pm 0.01^{\mathrm{a}}$ & $1.95 \pm 0.01^{\mathrm{b}}$ & $1.72 \pm 0.01^{\mathrm{c}}$ & $8.01 \pm 0.61^{\mathrm{A}}$ & $13.57 \pm 0.16^{\mathrm{B}}$ & $13.03 \pm 0.83^{\mathrm{B}}$ \\
\hline 14 & Pentadecanoic acid & $1.06 \pm 0.01^{\mathrm{a}}$ & $1.62 \pm 0.01^{\mathrm{b}}$ & $1.58 \pm 0.01^{\mathrm{c}}$ & $1.63 \pm 0.02^{\mathrm{A}}$ & $1.77 \pm 0.23^{\mathrm{AB}}$ & $1.97 \pm 0.03^{\mathrm{B}}$ \\
\hline 23 & Hexadecanoic acid & $4.03 \pm 0.29^{\mathrm{a}}$ & $6.88 \pm 0.20^{\mathrm{b}}$ & $5.21 \pm 0.22^{\mathrm{c}}$ & $12.63 \pm 0.79^{\mathrm{A}}$ & $10.68 \pm 0.13^{\mathrm{B}}$ & $9.79 \pm 0.69^{\mathrm{B}}$ \\
\hline 25 & Heptadecanoic acid & $1.34 \pm 0.05^{\mathrm{a}}$ & $1.95 \pm 0.04^{\mathrm{b}}$ & $1.83 \pm 0.02^{\mathrm{c}}$ & $1.76 \pm 0.02^{\mathrm{A}}$ & $1.83 \pm 0.02^{\mathrm{AB}}$ & $1.86 \pm 0.06^{\mathrm{B}}$ \\
\hline 33 & Octadecanoic acid & $1.86 \pm 0.04^{\mathrm{a}}$ & $2.69 \pm 0.05^{\mathrm{b}}$ & $2.57 \pm 0.04^{\mathrm{c}}$ & $2.59 \pm 0.03^{\mathrm{AB}}$ & $2.66 \pm 0.03^{\mathrm{A}}$ & $2.51 \pm 0.10^{\mathrm{B}}$ \\
\hline 40 & Eicosanoic acid & $1.07 \pm 0.02^{\mathrm{a}}$ & $1.60 \pm 0.01^{\mathrm{b}}$ & $1.57 \pm 0.01^{\mathrm{c}}$ & $1.56 \pm 0.01^{\mathrm{AB}}$ & $1.58 \pm 0.02^{\mathrm{A}}$ & $1.55 \pm 0.01^{\mathrm{B}}$ \\
\hline 47 & Docosanoic acid & $1.16 \pm 0.02^{\mathrm{a}}$ & $1.70 \pm 0.03^{\mathrm{b}}$ & $1.65 \pm 0.01^{\mathrm{c}}$ & $1.6 \pm 0.01^{\mathrm{A}}$ & $1.61 \pm 0.02^{\mathrm{A}}$ & $1.61 \pm 0.03^{\mathrm{A}}$ \\
\hline 49 & Tricosanoic acid & $1.06 \pm 0.01^{\mathrm{a}}$ & $1.59 \pm 0.01^{\mathrm{b}}$ & $1.56 \pm 0.01^{\mathrm{c}}$ & n.d & n.d & n.d \\
\hline 52 & Tetracosanoic acid & $1.07 \pm 0.01^{\mathrm{a}}$ & $1.61 \pm 0.01^{\mathrm{b}}$ & $1.57 \pm 0.01^{\mathrm{c}}$ & $1.54 \pm 0.01^{\mathrm{A}}$ & $1.57 \pm 0.01^{\mathrm{B}}$ & $1.55 \pm 0.00^{\mathrm{AB}}$ \\
\hline 59 & Octacosanoic acid & $1.09 \pm 0.03^{\mathrm{a}}$ & $1.68 \pm 0.01^{\mathrm{b}}$ & $1.63 \pm 0.04^{\mathrm{b}}$ & $1.6 \pm 0.05^{\mathrm{A}}$ & $1.65 \pm 0.13^{\mathrm{A}}$ & $1.62 \pm 0.05^{\mathrm{A}}$ \\
\hline 71 & Triacontanoic acid & $1.11 \pm 0.04^{\mathrm{a}}$ & $1.67 \pm 0.03^{\mathrm{b}}$ & $1.62 \pm 0.03^{\mathrm{b}}$ & $1.64 \pm 0.03^{\mathrm{A}}$ & $1.69 \pm 0.09^{\mathrm{A}}$ & $1.59 \pm 0.01^{\mathrm{A}}$ \\
\hline \multirow[t]{2}{*}{77} & Dotriacontanoic acid & $1.06 \pm 0.02^{\mathrm{a}}$ & $1.60 \pm 0.02^{\mathrm{b}}$ & $1.56 \pm 0.01^{\mathrm{c}}$ & n.d & n.d & n.d \\
\hline & Monounsaturated fatty acids & $6.72 \pm 0.10^{a}$ & $10.22 \pm 0.06^{b}$ & $9.91 \pm 0.04^{c}$ & $23.19 \pm 1.24^{A}$ & $25.23 \pm 0.31^{B}$ & $24.59 \pm 0.85^{A B}$ \\
\hline 11 & 9-Tetradecenoic acid & n.d & n.d & n.d & $1.54 \pm 0.01^{\mathrm{A}}$ & $1.58 \pm 0.02^{\mathrm{B}}$ & $1.57 \pm 0.01^{\mathrm{AB}}$ \\
\hline 20 & 9-hexadecenoic acid & $1.08 \pm 0.01^{\mathrm{a}}$ & $1.61 \pm 0.01^{\mathrm{b}}$ & $1.59 \pm 0.02^{\mathrm{b}}$ & $15.82 \pm 1.17^{\mathrm{A}}$ & $17.93 \pm 0.25^{\mathrm{B}}$ & $17.44 \pm 0.82^{\mathrm{AB}}$ \\
\hline 21 & 7-Hexadecenoic acid & $1.05 \pm 0.01^{\mathrm{a}}$ & $1.63 \pm 0.00^{\mathrm{b}}$ & $1.57 \pm 0.01^{\mathrm{c}}$ & $1.61 \pm 0.02^{\mathrm{A}}$ & $1.73 \pm 0.03^{\mathrm{B}}$ & $1.72 \pm 0.01^{\mathrm{B}}$ \\
\hline 31 & 9-Octadecenoic acid & $1.30 \pm 0.03^{\mathrm{a}}$ & $1.95 \pm 0.03^{\mathrm{b}}$ & $1.79 \pm 0.02^{\mathrm{c}}$ & $2.42 \pm 0.04^{\mathrm{A}}$ & $2.14 \pm 0.02^{\mathrm{B}}$ & $2.06 \pm 0.03^{\mathrm{C}}$ \\
\hline 32 & 11-Octadecenoic acid & $1.20 \pm 0.03^{\mathrm{a}}$ & $1.87 \pm 0.02^{\mathrm{b}}$ & $1.84 \pm 0.01^{\mathrm{b}}$ & $1.81 \pm 0.03^{\mathrm{A}}$ & $1.84 \pm 0.04^{\mathrm{A}}$ & $1.81 \pm 0.0^{\mathrm{A}}$ \\
\hline \multirow[t]{2}{*}{34} & Nonadecenoic acid & $2.10 \pm 0.03^{\mathrm{a}}$ & $3.16 \pm 0.01^{\mathrm{b}}$ & $3.11 \pm 0.02^{\mathrm{c}}$ & n.d & n.d & n.d \\
\hline & Polyunsaturated fatty acids & $8.72 \pm 0.29^{\mathrm{a}}$ & $18.24 \pm 0.45^{\mathrm{b}}$ & $15.17 \pm 0.16^{\mathrm{c}}$ & $30.44 \pm 0.87^{\mathrm{A}}$ & $34.46 \pm 0.87^{\mathrm{B}}$ & $33.92 \pm 0.78^{\mathrm{B}}$ \\
\hline 22 & Methyl-4,7,10,13-hexadecatetraenoate & $1.07 \pm 0.01^{\mathrm{a}}$ & $1.69 \pm 0.01^{\mathrm{b}}$ & $1.63 \pm 0.01^{\mathrm{c}}$ & $1.59 \pm 0.01^{\mathrm{AB}}$ & $1.61 \pm 0.02^{\mathrm{A}}$ & $1.58 \pm 0.01^{\mathrm{B}}$ \\
\hline 16 & $\mathrm{C} 16: 4 \omega 3$ & n.d & n.d & n.d & n.d & $1.56 \pm 0.02^{\mathrm{A}}$ & $1.55 \pm 0.00^{\mathrm{A}}$ \\
\hline 17 & $\mathrm{C} 16: 2 \omega 6$ & n.d & n.d & n.d & $1.55 \pm 0.01^{\mathrm{A}}$ & $1.74 \pm 0.02^{\mathrm{B}}$ & $1.72 \pm 0.01^{\mathrm{B}}$ \\
\hline 18 & $\mathrm{C} 16: 3 \omega 3$ & n.d & n.d & n.d & $1.56 \pm 0.01^{\mathrm{A}}$ & $1.59 \pm 0.02^{\mathrm{B}}$ & $1.57 \pm 0.00^{\mathrm{A}}$ \\
\hline 19 & 7,12-Hexadienoic acid & n.d & $1.67 \pm 0.01^{\mathrm{a}}$ & $1.58 \pm 0.01^{\mathrm{c}}$ & n.d & n.d & n.d \\
\hline 27 & $3,6,9,12,15$-Octadecapentaenoic acid & n.d & n.d & n.d & $1.56 \pm 0.01^{\mathrm{A}}$ & $1.74 \pm 0.03^{\mathrm{B}}$ & $1.76 \pm 0.02^{\mathrm{B}}$ \\
\hline 29 & 9,12 -Octadecadienoic acid ${ }^{1}$ & $1.38 \pm 0.04^{\mathrm{a}}$ & $2.21 \pm 0.07^{\mathrm{b}}$ & $2.15 \pm 0.04^{\mathrm{b}}$ & $3.72 \pm 0.04^{\mathrm{A}}$ & $3.49 \pm 0.05^{\mathrm{B}}$ & $3.39 \pm 0.05^{\mathrm{C}}$ \\
\hline 30 & $9,12,15$-Octadecatrienoic acid & $2.55 \pm 0.15^{\mathrm{a}}$ & $5.24 \pm 0.16^{\mathrm{b}}$ & $3.49 \pm 0.08^{\mathrm{c}}$ & $1.71 \pm 0.02^{\mathrm{A}}$ & $1.73 \pm 0.03^{\mathrm{A}}$ & $1.69 \pm 0.04^{\mathrm{A}}$ \\
\hline 36 & 5,8,11,14,17-Eicosapentaenoic acid & $1.59 \pm 0.07^{\mathrm{a}}$ & $3.95 \pm 0.17^{\mathrm{b}}$ & $2.95 \pm 0.07^{\mathrm{c}}$ & $8.72 \pm 0.40^{\mathrm{A}}$ & $10.16 \pm 0.26^{\mathrm{B}}$ & $9.95 \pm 0.25^{\mathrm{B}}$ \\
\hline 41 & $4,7,10,13,16,19$-Docosahexaenoic acid & $1.06 \pm 0.01^{\mathrm{a}}$ & $1.74 \pm 0.03^{\mathrm{b}}$ & $1.68 \pm 0.01^{\mathrm{c}}$ & $4.69 \pm 0.22^{\mathrm{A}}$ & $5.21 \pm 0.28^{\mathrm{A}}$ & $5.17 \pm 0.33^{\mathrm{A}}$ \\
\hline 42 & 7,10,13,16,19-Docosapentaenoic acid & $1.07 \pm 0.02^{\mathrm{a}}$ & $1.75 \pm 0.03^{\mathrm{b}}$ & $1.69 \pm 0.00^{\mathrm{c}}$ & $3.46 \pm 0.13^{\mathrm{A}}$ & $3.26 \pm 0.10^{\mathrm{A}}$ & $3.29 \pm 0.21^{\mathrm{A}}$ \\
\hline \multirow[t]{2}{*}{43} & 4,7,10,13,16-Docosapentaenoic acid & n.d & n.d & n.d & $1.89 \pm 0.03^{\mathrm{A}}$ & $2.35 \pm 0.06^{\mathrm{B}}$ & $2.26 \pm 0.04^{\mathrm{B}}$ \\
\hline & Aliphatic alcohols & $23.74 \pm 1.19^{a}$ & $35.14 \pm 0.91^{b}$ & $30.54 \pm 0.62^{c}$ & $26.62 \pm 1.25^{A}$ & $32.35 \pm 0.75^{B}$ & $33.87 \pm 1.76^{B}$ \\
\hline 2 & Decanol & $1.46 \pm 0.04^{\mathrm{a}}$ & $2.48 \pm 0.05^{\mathrm{b}}$ & $1.91 \pm 0.57^{\mathrm{ab}}$ & $1.6 \pm 0.13^{\mathrm{A}}$ & $1.83 \pm 0.03^{\mathrm{B}}$ & $1.94 \pm 0.08^{\mathrm{B}}$ \\
\hline 4 & Undecanol & $1.68 \pm 0.04^{\mathrm{a}}$ & $2.67 \pm 0.03^{\mathrm{b}}$ & $2.14 \pm 0.57^{\mathrm{ab}}$ & $1.73 \pm 0.18^{\mathrm{A}}$ & $2.28 \pm 0.06^{\mathrm{B}}$ & $2.44 \pm 0.10^{\mathrm{B}}$ \\
\hline 7 & Dodecanol & $1.17 \pm 0.03^{\mathrm{a}}$ & $1.86 \pm 0.04^{\mathrm{b}}$ & $1.73 \pm 0.19^{b}$ & $1.47 \pm 0.06^{\mathrm{A}}$ & $1.75 \pm 0.04^{\mathrm{B}}$ & $1.84 \pm 0.06^{\mathrm{B}}$ \\
\hline 9 & Tridecanol & $1.33 \pm 0.07^{\mathrm{a}}$ & $2.03 \pm 0.04^{\mathrm{b}}$ & $1.90 \pm 0.16^{\mathrm{b}}$ & $1.73 \pm 0.05^{\mathrm{A}}$ & $2.15 \pm 0.06^{\mathrm{B}}$ & $2.38 \pm 0.15^{\mathrm{C}}$ \\
\hline 10 & Tetradecanol & $1.06 \pm 0.02^{\mathrm{a}}$ & $1.59 \pm 0.02^{\mathrm{b}}$ & $1.49 \pm 0.01^{\mathrm{c}}$ & $1.45 \pm 0.02^{\mathrm{A}}$ & $1.50 \pm 0.03^{\mathrm{AB}}$ & $1.50 \pm 0.03^{\mathrm{B}}$ \\
\hline 15 & Hexadecanol & $3.09 \pm 0.31^{\mathrm{a}}$ & $4.13 \pm 0.21^{\mathrm{b}}$ & $3.40 \pm 0.23^{\mathrm{a}}$ & $3.07 \pm 0.25^{\mathrm{A}}$ & $3.24 \pm 0.34^{\mathrm{A}}$ & $3.58 \pm 0.44^{\mathrm{A}}$ \\
\hline 24 & Octadece-9-nol & $4.40 \pm 0.54^{\mathrm{a}}$ & $5.88 \pm 0.39^{b}$ & $4.70 \pm 0.41^{\mathrm{a}}$ & $4.07 \pm 0.38^{\mathrm{A}}$ & $4.38 \pm 0.50^{\mathrm{A}}$ & $4.99 \pm 0.72^{\mathrm{A}}$ \\
\hline 26 & Octadecanol & $2.12 \pm 0.17^{\mathrm{a}}$ & $2.88 \pm 0.12^{\mathrm{b}}$ & $2.48 \pm 0.14^{\mathrm{c}}$ & $2.24 \pm 0.14^{\mathrm{A}}$ & $2.42 \pm 0.18^{\mathrm{A}}$ & $2.60 \pm 0.24^{\mathrm{A}}$ \\
\hline
\end{tabular}


Table 3 (continued)

\begin{tabular}{|c|c|c|c|c|c|c|c|}
\hline \multirow[t]{2}{*}{ No } & \multirow[t]{2}{*}{ Identified compounds } & \multicolumn{3}{|c|}{ Hemiselmis cf. andersenii } & \multicolumn{3}{|l|}{ Pavlova pinguis } \\
\hline & & Low & Medium & High & Low & Medium & High \\
\hline 28 & 3,7,11,15-Tetramethyl-2-hexadecen-1-ol & $1.58 \pm 0.07^{\mathrm{a}}$ & $3.04 \pm 0.07^{b}$ & $2.50 \pm 0.03^{\mathrm{c}}$ & $2.73 \pm 0.09^{\mathrm{A}}$ & $4.77 \pm 0.06^{\mathrm{B}}$ & $4.44 \pm 0.18^{\mathrm{C}}$ \\
\hline 37 & Eicosanol & $0.93 \pm 0.03^{\mathrm{a}}$ & $1.37 \pm 0.01^{\mathrm{b}}$ & $1.33 \pm 0.00^{\mathrm{c}}$ & $1.31 \pm 0.01^{\mathrm{A}}$ & $1.32 \pm 0.02^{\mathrm{A}}$ & $1.33 \pm 0.02^{\mathrm{A}}$ \\
\hline 44 & Docosanol & $0.86 \pm 0.01^{\mathrm{a}}$ & $1.30 \pm 0.02^{\mathrm{b}}$ & $1.28 \pm 0.01^{\mathrm{c}}$ & $1.26 \pm 0.01^{\mathrm{A}}$ & $1.29 \pm 0.02^{\mathrm{B}}$ & $1.27 \pm 0.01^{\mathrm{AB}}$ \\
\hline 53 & Hexacosanol & n.d & n.d & n.d & n.d & $1.27 \pm 0.01^{\mathrm{A}}$ & $1.25 \pm 0.00^{\mathrm{A}}$ \\
\hline 56 & Octacosanol & $1.14 \pm 0.06^{\mathrm{a}}$ & $1.63 \pm 0.04^{\mathrm{b}}$ & $1.56 \pm 0.04^{\mathrm{b}}$ & $1.55 \pm 0.05^{\mathrm{A}}$ & $1.58 \pm 0.05^{\mathrm{A}}$ & $1.57 \pm 0.07^{\mathrm{A}}$ \\
\hline 66 & Octacosane-1,3-diol & $0.98 \pm 0.03^{\mathrm{a}}$ & $1.44 \pm 0.03^{\mathrm{b}}$ & $1.39 \pm 0.02^{\mathrm{c}}$ & n.d & n.d & n.d \\
\hline 68 & Tricosanol & $1.05 \pm 0.04^{\mathrm{a}}$ & $1.52 \pm 0.04^{\mathrm{b}}$ & $1.46 \pm 0.03^{\mathrm{b}}$ & $1.44 \pm 0.03^{\mathrm{A}}$ & $1.45 \pm 0.03^{\mathrm{A}}$ & $1.43 \pm 0.05^{\mathrm{A}}$ \\
\hline \multirow[t]{2}{*}{74} & Dotriacontanol & $0.88 \pm 0.01^{\mathrm{a}}$ & $1.32 \pm 0.02^{\mathrm{b}}$ & $1.29 \pm 0.01^{\mathrm{c}}$ & $1.31 \pm 0.01^{\mathrm{A}}$ & $1.47 \pm 0.13^{\mathrm{B}}$ & $1.30 \pm 0.01^{\mathrm{A}}$ \\
\hline & Sterols & $1.99 \pm 0.21^{a}$ & $3.79 \pm 0.20^{b}$ & $3.18 \pm 0.18^{c}$ & $14.39 \pm 1.13^{A}$ & $20.03 \pm 0.30^{B}$ & $18.02 \pm 0.47^{C}$ \\
\hline 54 & 22-Stigmasten-3-one & n.d & n.d & n.d & $0.30 \pm 0.04^{\mathrm{A}}$ & $0.32 \pm 0.02^{\mathrm{A}}$ & $0.30 \pm 0.01^{\mathrm{A}}$ \\
\hline 57 & $24 \beta$-Methylcholesta-5,22E-dien-3 $\beta$-ol & $0.85 \pm 0.08^{\mathrm{a}}$ & $2.10 \pm 0.18^{\mathrm{b}}$ & $1.78 \pm 0.09^{\mathrm{c}}$ & n.d & n.d & n.d \\
\hline 58 & $24 \alpha$-Methylcholest-5-en-3 $\beta$-ol & $0.22 \pm 0.03^{\mathrm{a}}$ & $0.40 \pm 0.07^{\mathrm{b}}$ & $0.33 \pm 0.05^{\mathrm{b}}$ & $0.52 \pm 0.07^{\mathrm{A}}$ & $0.74 \pm 0.06^{\mathrm{B}}$ & $0.76 \pm 0.06^{\mathrm{B}}$ \\
\hline 60 & $24 \beta$-Ethylcholesta-5,22E-dien- $3 \beta$-ol & n.d & n.d & n.d & $0.44 \pm 0.08^{\mathrm{A}}$ & $0.41 \pm 0.02^{\mathrm{B}}$ & $0.58 \pm 0.06^{\mathrm{C}}$ \\
\hline 61 & $24 \alpha$-Ethylcholesta-5,22E-dien- $3 \beta$-ol & n.d & n.d & n.d & $4.71 \pm 0.37^{\mathrm{A}}$ & $8.32 \pm 0.31^{\mathrm{B}}$ & $7.15 \pm 0.22^{C}$ \\
\hline 62 & 24-Ethyl- $\delta(22)$-coprostenol & n.d & n.d & n.d & $0.49 \pm 0.04^{\mathrm{A}}$ & $0.92 \pm 0.18^{\mathrm{B}}$ & $0.83 \pm 0.07^{\mathrm{B}}$ \\
\hline 63 & $24 \alpha$-Ethylcholest-5-en-3 $\beta$-ol & $0.74 \pm 0.10^{\mathrm{a}}$ & $0.98 \pm 0.08^{\mathrm{b}}$ & $0.83 \pm 0.09^{\mathrm{ab}}$ & $0.94 \pm 0.18^{\mathrm{A}}$ & $1.22 \pm 0.04^{\mathrm{A}}$ & $1.20 \pm 0.26^{\mathrm{A}}$ \\
\hline 64 & Stigmasta-3,5-dien-7-one & $0.18 \pm 0.01^{\mathrm{a}}$ & $0.31 \pm 0.02^{\mathrm{b}}$ & $0.25 \pm 0.01^{\mathrm{c}}$ & $0.41 \pm 0.08^{\mathrm{A}}$ & n.d & $0.28 \pm 0.03^{\mathrm{B}}$ \\
\hline 65 & $4 \alpha, 24$-Dimethyl- $5 \alpha$-cholestan-3 $\beta$-ol & n.d & n.d & n.d & $0.95 \pm 0.12^{\mathrm{A}}$ & $1.10 \pm 0.03^{\mathrm{B}}$ & $0.93 \pm 0.05^{\mathrm{A}}$ \\
\hline 67 & Unidentified Sterol & n.d & n.d & n.d & $1.26 \pm 0.10^{\mathrm{A}}$ & $1.83 \pm 0.12^{\mathrm{B}}$ & $1.57 \pm 0.07^{\mathrm{C}}$ \\
\hline 69 & $\begin{array}{l}4 \alpha \text {-methyl,24-ethyl-5 } \alpha \text {-cholest-22E-en- } \\
3 \beta \text {-ol }\end{array}$ & n.d & n.d & n.d & $0.80 \pm 0.07^{\mathrm{AB}}$ & $0.91 \pm 0.08^{\mathrm{A}}$ & $0.76 \pm 0.00^{\mathrm{B}}$ \\
\hline 70 & $4 \alpha$-methyl,24-ethyl-5 $\alpha$-cholestan-3-ol & n.d & n.d & n.d & $0.80 \pm 0.07^{\mathrm{A}}$ & $1.05 \pm 0.17^{\mathrm{B}}$ & $0.71 \pm 0.10^{\mathrm{A}}$ \\
\hline 72 & $4 \alpha, 24 \beta$-dimethyl- $5 \alpha$-cholestan- $3 \beta, 4 \beta$-diol $*$ & n.d & n.d & n.d & $0.41 \pm 0.03^{\mathrm{A}}$ & $0.53 \pm 0.03^{\mathrm{B}}$ & $0.45 \pm 0.02^{\mathrm{A}}$ \\
\hline 73 & Unidentified sterol & n.d & n.d & n.d & $1.26 \pm 0.04^{\mathrm{A}}$ & $1.26 \pm 0.17^{\mathrm{A}}$ & $0.98 \pm 0.07^{\mathrm{B}}$ \\
\hline \multirow[t]{2}{*}{75} & $\begin{array}{l}4 \alpha \text {-methyl-24 } \beta \text {-ethyl- } 5 \alpha \text {-cholestan- } 3 \beta, 4 \beta \text { - } \\
\text { diol* }\end{array}$ & n.d & n.d & n.d & $1.1 \pm 0.23^{\mathrm{A}}$ & $1.45 \pm 0.17^{\mathrm{A}}$ & $1.51 \pm 0.37^{\mathrm{A}}$ \\
\hline & Monoglycerides & $1.48 \pm 0.04^{a}$ & $1.64 \pm 0.18^{a}$ & $0.99 \pm 0.07^{b}$ & $1.45 \pm 0.09^{A}$ & $1.24 \pm 0.07^{B}$ & $0.98 \pm 0.03^{C}$ \\
\hline 38 & 1,3-Dihydroxy-2-propanyl myristate & n.d & n.d & n.d & $0.14 \pm 0.01^{\mathrm{A}}$ & $0.10 \pm 0.00^{\mathrm{B}}$ & $0.08 \pm 0.01^{\mathrm{C}}$ \\
\hline 39 & 2,3-Dihydroxypropyl myristate & n.d & n.d & n.d & $0.23 \pm 0.01^{\mathrm{A}}$ & $0.20 \pm 0.03^{\mathrm{A}}$ & $0.10 \pm 0.01^{\mathrm{B}}$ \\
\hline 45 & 1,3-Dihydroxy-2-propanyl palmitate & $0.06 \pm 0.00^{\mathrm{a}}$ & $0.12 \pm 0.02^{\mathrm{b}}$ & $0.08 \pm 0.01^{\mathrm{c}}$ & $0.21 \pm 0.01^{\mathrm{A}}$ & $0.12 \pm 0.01^{\mathrm{B}}$ & $0.13 \pm 0.01^{\mathrm{B}}$ \\
\hline 46 & 2,3-Dihydroxypropyl palmitate & $0.75 \pm 0.02^{\mathrm{a}}$ & $0.76 \pm 0.06^{\mathrm{a}}$ & $0.43 \pm 0.04^{\mathrm{b}}$ & $0.55 \pm 0.03^{\mathrm{A}}$ & $0.40 \pm 0.04^{\mathrm{B}}$ & $0.30 \pm 0.05^{\mathrm{C}}$ \\
\hline 48 & 3-Octadecoxypropane-1,2-diol & $0.06 \pm 0.01^{\mathrm{a}}$ & $0.09 \pm 0.02^{\mathrm{b}}$ & $0.10 \pm 0.01^{\mathrm{b}}$ & $0.05 \pm 0.01^{\mathrm{A}}$ & $0.07 \pm 0.02^{\mathrm{A}}$ & $0.07 \pm 0.00^{\mathrm{A}}$ \\
\hline 50 & 1,3-Dihydroxy-2-propanyl stearate & $0.05 \pm 0.01^{\mathrm{a}}$ & $0.12 \pm 0.01^{\mathrm{b}}$ & $0.07 \pm 0.00^{\mathrm{a}}$ & $0.05 \pm 0.01^{\mathrm{A}}$ & $0.07 \pm 0.01^{\mathrm{B}}$ & $0.09 \pm 0.02^{\mathrm{B}}$ \\
\hline \multirow[t]{2}{*}{51} & 2,3-Dihydroxypropyl stearate & $0.56 \pm 0.02^{\mathrm{a}}$ & $0.54 \pm 0.07^{\mathrm{a}}$ & $0.31 \pm 0.02^{\mathrm{b}}$ & $0.22 \pm 0.02^{\mathrm{A}}$ & $0.28 \pm 0.03^{\mathrm{B}}$ & $0.24 \pm 0.02^{\mathrm{AB}}$ \\
\hline & Others & $0.13 \pm 0.01^{a}$ & $0.20 \pm 0.01^{b}$ & $0.23 \pm 0.04^{c}$ & $0.58 \pm 0.04^{A}$ & $0.44 \pm 0.06^{B}$ & $0.31 \pm 0.05^{C}$ \\
\hline 5 & 2,6-bis(1,1-Dimethylethyl)phenol & $0.13 \pm 0.01^{\mathrm{a}}$ & $0.18 \pm 0.01^{\mathrm{b}}$ & $0.19 \pm 0.02^{\mathrm{b}}$ & $0.14 \pm 0.02^{\mathrm{A}}$ & $0.16 \pm 0.01^{\mathrm{A}}$ & $0.14 \pm 0.02^{\mathrm{A}}$ \\
\hline 13 & Rhamnose & n.d & n.d & n.d & n.d & n.d & n.d \\
\hline 55 & $\alpha$-Tocopherol & n.d & $0.03 \pm 0.00^{\mathrm{a}}$ & $0.04 \pm 0.01^{\mathrm{b}}$ & $0.10 \pm 0.01^{\mathrm{A}}$ & $0.04 \pm 0.01^{\mathrm{B}}$ & $0.12 \pm 0.01^{\mathrm{C}}$ \\
\hline 76 & Campestenyl glycoside & n.d & n.d & n.d & $0.17 \pm 0.03^{\mathrm{A}}$ & $0.14 \pm 0.03^{\mathrm{A}}$ & $0.07 \pm 0.02^{\mathrm{B}}$ \\
\hline \multirow[t]{2}{*}{78} & Campesteryl glycoside & n.d & n.d & n.d & $0.17 \pm 0.02^{\mathrm{A}}$ & $0.08 \pm 0.01^{\mathrm{B}}$ & n.d \\
\hline & Total & $60.85 \pm 2.30^{a}$ & $97.35 \pm 2.11^{b}$ & $85.66 \pm 0.27^{c}$ & $137.38 \pm 1.83^{A}$ & $157.02 \pm 0.96^{B}$ & $154.96 \pm 2.08^{B}$ \\
\hline
\end{tabular}

Values (means \pm SD of four replicates) in the same row, not sharing a common superscript, are significantly different $(p<0.05)$. Differences among treatments assessed by one-way ANOVA followed by Tukey post-hoc analysis are represented by superscript lowercase letters for $H$. cf. andersenii, and by superscript uppercase letters for P. pinguis. All the compounds containing hydroxyl and/or carboxyl groups are identified as the correspondent trimethylsilyl (TMS) derivatives. ${ }^{1}$ Contains cis and trans isomers. n.d., non detected. * identified as mono-TMS ether

(often called Kennedy pathway) and an acyl-CoA-independent pathway (Cagliari et al. 2011). In the Kennedy pathway, the intermediates phosphatidic acid and diacylglycerol are also used for the synthesis of phospholipids (Li et al. 2013).
For both microalgae, the greatest amounts of monoglycerides were verified for the treatments with low phosphorus loadings (LP and MP treatments). For P. pinguis, the greatest increase in fatty acid levels after alkaline hydrolysis 
Table 4 Lipid profile $\left(\mathrm{mg} \mathrm{g}^{-1} \mathrm{dw}\right)$ of Hemiselmis cf. andersenii and Pavlova pinguis grown in different initial phosphorus loadings after alkaline hydrolysis

\begin{tabular}{|c|c|c|c|c|c|c|c|}
\hline \multirow[t]{2}{*}{ No } & \multirow[t]{2}{*}{ Identified compounds } & \multicolumn{3}{|c|}{ Hemiselmis cf. andersenii } & \multicolumn{3}{|l|}{ Pavlova pinguis } \\
\hline & & Low & Medium & High & Low & Medium & High \\
\hline & Fatty acids & $44.13 \pm 0.34^{a}$ & $77.42 \pm 4.86^{b}$ & $72.62 \pm 3.52^{b}$ & $132.79 \pm 3.70^{A}$ & $134.16 \pm 3.29^{A}$ & $119.34 \pm 2.12^{B}$ \\
\hline & Saturated fatty acids & $18.65 \pm 0.11^{a}$ & $32.54 \pm 1.95^{b}$ & $30.92 \pm 1.87^{b}$ & $59.49 \pm 3.56^{A}$ & $59.23 \pm 1.77^{A}$ & $51.69 \pm 1.65^{B}$ \\
\hline 1 & Nonanoic acid & $1.54 \pm 0.01^{\mathrm{a}}$ & $2.05 \pm 0.02^{\mathrm{b}}$ & $2.02 \pm 0.04^{\mathrm{b}}$ & $2.01 \pm 0.05^{\mathrm{A}}$ & $2.03 \pm 0.02^{\mathrm{A}}$ & $2.02 \pm 0.01^{\mathrm{A}}$ \\
\hline 3 & Decanoic acid & n.d & n.d & n.d & $2.00 \pm 0.05^{\mathrm{A}}$ & $2.03 \pm 0.02^{\mathrm{A}}$ & $2.03 \pm 0.01^{\mathrm{A}}$ \\
\hline 6 & Undecanoic acid & n.d & n.d & n.d & $2.06 \pm 0.00^{\mathrm{A}}$ & n.d & $2.01 \pm 0.01^{\mathrm{B}}$ \\
\hline 8 & Dodecanoic acid & n.d & n.d & n.d & $2.02 \pm 0.05^{\mathrm{A}}$ & $2.04 \pm 0.02^{\mathrm{A}}$ & $2.03 \pm 0.01^{\mathrm{A}}$ \\
\hline 12 & Tetradecanoic acid & $1.81 \pm 0.02^{\mathrm{a}}$ & $4.15 \pm 0.26^{\mathrm{b}}$ & $3.56 \pm 0.38^{c}$ & $13.39 \pm 0.67^{\mathrm{A}}$ & $18.68 \pm 0.22^{\mathrm{B}}$ & $15.69 \pm 0.32^{\mathrm{C}}$ \\
\hline 14 & Pentadecanoic acid & $1.57 \pm 0.00^{\mathrm{a}}$ & $2.19 \pm 0.04^{\mathrm{b}}$ & $2.12 \pm 0.01^{\mathrm{c}}$ & $2.18 \pm 0.06^{\mathrm{A}}$ & $2.63 \pm 0.02^{\mathrm{B}}$ & $2.53 \pm 0.02^{\mathrm{C}}$ \\
\hline 23 & Hexadecanoic acid & $7.56 \pm 0.07^{\mathrm{a}}$ & $13.69 \pm 1.25^{\mathrm{b}}$ & $11.03 \pm 1.41^{\mathrm{c}}$ & $19.11 \pm 0.43^{\mathrm{A}}$ & $14.65 \pm 0.68^{\mathrm{B}}$ & $11.75 \pm 0.25^{\mathrm{C}}$ \\
\hline 25 & Heptadecanoic acid & $1.69 \pm 0.01^{\mathrm{a}}$ & $2.28 \pm 0.05^{\mathrm{b}}$ & $2.28 \pm 0.01^{\mathrm{b}}$ & $2.20 \pm 0.10^{\mathrm{A}}$ & $2.29 \pm 0.04^{\mathrm{A}}$ & $2.21 \pm 0.01^{\mathrm{A}}$ \\
\hline 33 & Octadecanoic acid & $2.96 \pm 0.07^{\mathrm{a}}$ & $4.05 \pm 0.27^{\mathrm{b}}$ & $3.79 \pm 0.18^{b}$ & $7.00 \pm 0.03^{\mathrm{A}}$ & $4.37 \pm 0.65^{\mathrm{B}}$ & $3.61 \pm 0.06^{\mathrm{B}}$ \\
\hline 40 & Eicosanoic acid & n.d & $2.06 \pm 0.03^{\mathrm{a}}$ & $2.03 \pm 0.03^{\mathrm{a}}$ & $2.07 \pm 0.08^{\mathrm{A}}$ & $2.08 \pm 0.03^{\mathrm{A}}$ & $2.06 \pm 0.01^{\mathrm{A}}$ \\
\hline 47 & Docosanoic acid & $1.54 \pm 0.02^{\mathrm{a}}$ & $2.07 \pm 0.04^{\mathrm{b}}$ & $2.07 \pm 0.02^{\mathrm{b}}$ & $2.09 \pm 0.07^{\mathrm{A}}$ & $2.14 \pm 0.03^{\mathrm{A}}$ & $2.11 \pm 0.02^{\mathrm{A}}$ \\
\hline 52 & Tetracosanoic acid & n.d & n.d & $2.01 \pm 0.02$ & $2.00 \pm 0.05^{\mathrm{A}}$ & $2.04 \pm 0.02^{\mathrm{A}}$ & n.d \\
\hline 59 & Octacosanoic acid & n.d & n.d & n.d & $2.01 \pm 0.05^{\mathrm{A}}$ & $2.04 \pm 0.02^{\mathrm{A}}$ & $2.03 \pm 0.01^{\mathrm{A}}$ \\
\hline \multirow[t]{2}{*}{71} & Triacontanoic acid & n.d & n.d & n.d & $2.11 \pm 0.07^{\mathrm{A}}$ & $2.21 \pm 0.02^{\mathrm{B}}$ & $2.11 \pm 0.06^{\mathrm{AB}}$ \\
\hline & Monounsaturated fatty acids & $10.30 \pm 0.03^{a}$ & $14.33 \pm 0.42^{b}$ & $14.20 \pm 0.08^{b}$ & $32.02 \pm 0.29^{A}$ & $33.12 \pm 0.65^{B}$ & $29.72 \pm 0.34^{C}$ \\
\hline 11 & 9-Tetradecenoic acid & n.d & n.d & n.d & $2.03 \pm 0.02^{\mathrm{A}}$ & $2.05 \pm 0.02^{\mathrm{A}}$ & $2.04 \pm 0.01^{\mathrm{A}}$ \\
\hline 20 & 9-Hexadecenoic acid & $1.60 \pm 0.00^{\mathrm{a}}$ & $2.16 \pm 0.03^{\mathrm{b}}$ & $2.15 \pm 0.01^{\mathrm{b}}$ & $20.98 \pm 0.90^{\mathrm{A}}$ & $23.22 \pm 0.25^{\mathrm{B}}$ & $20.41 \pm 0.32^{\mathrm{A}}$ \\
\hline 21 & 7-Hexadecenoic acid & $1.56 \pm 0.01^{\mathrm{a}}$ & $2.22 \pm 0.04^{\mathrm{b}}$ & $2.15 \pm 0.02^{\mathrm{c}}$ & $2.11 \pm 0.04^{\mathrm{A}}$ & $2.23 \pm 0.02^{\mathrm{B}}$ & $2.20 \pm 0.01^{\mathrm{B}}$ \\
\hline 31 & 9-Octadecenoic acid & $1.99 \pm 0.01^{\mathrm{a}}$ & $2.75 \pm 0.15^{\mathrm{b}}$ & $2.65 \pm 0.05^{\mathrm{b}}$ & $3.92 \pm 0.35^{\mathrm{A}}$ & $3.06 \pm 0.18^{\mathrm{B}}$ & $2.72 \pm 0.02^{\mathrm{B}}$ \\
\hline 32 & 11-Octadecenoic acid & $1.98 \pm 0.02^{\mathrm{a}}$ & $2.98 \pm 0.14^{\mathrm{b}}$ & $3.09 \pm 0.02^{\mathrm{b}}$ & $2.99 \pm 0.49^{\mathrm{A}}$ & $2.56 \pm 0.19^{\mathrm{AB}}$ & $2.35 \pm 0.02^{\mathrm{B}}$ \\
\hline \multirow[t]{2}{*}{34} & Nonadecenoic acid & $3.16 \pm 0.02^{\mathrm{a}}$ & $4.22 \pm 0.06^{\mathrm{b}}$ & $4.15 \pm 0.07^{\mathrm{b}}$ & n.d & n.d & n.d \\
\hline & Polyunsaturated fatty acids & $15.18 \pm 0.38^{a}$ & $30.56 \pm 2.51^{b}$ & $27.51 \pm 1.73^{b}$ & $41.29 \pm 0.11^{A}$ & $41.82 \pm 0.89^{A}$ & $37.93 \pm 0.28^{B}$ \\
\hline 22 & Methyl-4,7,10,13-hexadecatetraenoate & $1.54 \pm 0.01^{\mathrm{a}}$ & $2.14 \pm 0.04^{\mathrm{b}}$ & $2.07 \pm 0.01^{\mathrm{c}}$ & $2.03 \pm 0.03^{\mathrm{A}}$ & $2.06 \pm 0.03^{\mathrm{A}}$ & $2.04 \pm 0.01^{\mathrm{A}}$ \\
\hline 16 & $\mathrm{C} 16: 4 \omega 3$ & n.d & n.d & n.d & $2.04 \pm 0.03^{\mathrm{A}}$ & $2.05 \pm 0.02^{\mathrm{A}}$ & n.d \\
\hline 17 & $\mathrm{C} 16: 2 \omega 6$ & n.d & n.d & n.d & $2.03 \pm 0.04^{\mathrm{A}}$ & $2.19 \pm 0.02^{\mathrm{B}}$ & $2.18 \pm 0.01^{\mathrm{B}}$ \\
\hline 18 & $\mathrm{C} 16: 3 \omega 3$ & n.d & n.d & n.d & $2.05 \pm 0.07^{\mathrm{A}}$ & $2.12 \pm 0.02^{\mathrm{AB}}$ & $2.17 \pm 0.02^{\mathrm{B}}$ \\
\hline 19 & 7,12-Hexadienoic acid & n.d & $2.35 \pm 0.05^{\mathrm{a}}$ & $2.26 \pm 0.03^{\mathrm{b}}$ & n.d & n.d & n.d \\
\hline 27 & $3,6,9,12,15$-Octadecapentaenoic acid & n.d & n.d & n.d & $2.03 \pm 0.05^{\mathrm{A}}$ & $2.21 \pm 0.02^{\mathrm{B}}$ & $2.23 \pm 0.01^{\mathrm{B}}$ \\
\hline 29 & 9,12-Octadecadienoic acid ${ }^{1}$ & $2.52 \pm 0.13^{\mathrm{a}}$ & $3.62 \pm 0.28^{\mathrm{b}}$ & $3.59 \pm 0.15^{\mathrm{b}}$ & $5.01 \pm 0.26^{\mathrm{A}}$ & $4.56 \pm 0.15^{\mathrm{B}}$ & $4.33 \pm 0.02^{\mathrm{B}}$ \\
\hline 30 & $9,12,15$-Octadecatrienoic acid & $5.24 \pm 0.24^{\mathrm{a}}$ & $10.86 \pm 1.15^{\mathrm{b}}$ & $8.55 \pm 0.83^{c}$ & $2.44 \pm 0.03^{\mathrm{A}}$ & $2.20 \pm 0.04^{\mathrm{B}}$ & $2.13 \pm 0.01^{\mathrm{C}}$ \\
\hline 36 & 5,8,11,14,17-Eicosapentaenoic acid & $2.70 \pm 0.06^{\mathrm{a}}$ & $6.72 \pm 0.74^{\mathrm{b}}$ & $6.19 \pm 0.59^{b}$ & $11.29 \pm 0.39^{\mathrm{A}}$ & $10.90 \pm 0.28^{\mathrm{A}}$ & $10.05 \pm 0.06^{\mathrm{B}}$ \\
\hline 41 & 4,7,10,13,16,19-Docosahexaenoic acid & $1.57 \pm 0.02^{\mathrm{a}}$ & $2.41 \pm 0.20^{\mathrm{b}}$ & $2.43 \pm 0.11^{\mathrm{b}}$ & $5.71 \pm 0.09^{\mathrm{A}}$ & $6.63 \pm 0.20^{\mathrm{B}}$ & $6.15 \pm 0.12^{\mathrm{C}}$ \\
\hline 42 & 7,10,13,16,19-Docosapentaenoic acid & $1.59 \pm 0.02^{\mathrm{a}}$ & $2.44 \pm 0.17^{\mathrm{b}}$ & $2.42 \pm 0.13^{\mathrm{b}}$ & $4.18 \pm 0.03^{\mathrm{A}}$ & $3.99 \pm 0.09^{\mathrm{B}}$ & $3.90 \pm 0.03^{\mathrm{B}}$ \\
\hline \multirow[t]{2}{*}{43} & $4,7,10,13,16$-Docosapentaenoic acid & n.d & n.d & n.d & $2.48 \pm 0.02^{\mathrm{A}}$ & $2.89 \pm 0.05^{\mathrm{B}}$ & $2.76 \pm 0.03^{\mathrm{C}}$ \\
\hline & Aliphatic alcohols & $23.80 \pm 1.32^{a}$ & $35.71 \pm 1.46^{b}$ & $35.14 \pm 0.30^{b}$ & $33.20 \pm 1.19^{A}$ & $31.29 \pm 0.32^{B}$ & $31.03 \pm 0.14^{B}$ \\
\hline 2 & Decanol & $1.25 \pm 0.00^{\mathrm{a}}$ & $1.69 \pm 0.01^{\mathrm{b}}$ & $1.63 \pm 0.03^{\mathrm{ab}}$ & $1.63 \pm 0.04^{\mathrm{A}}$ & $1.65 \pm 0.02^{\mathrm{A}}$ & $1.64 \pm 0.01^{\mathrm{A}}$ \\
\hline 4 & Undecanol & $1.25 \pm 0.01^{\mathrm{a}}$ & $1.79 \pm 0.03^{\mathrm{b}}$ & $1.63 \pm 0.03^{\mathrm{ab}}$ & $1.66 \pm 0.03^{\mathrm{AB}}$ & $1.69 \pm 0.03^{\mathrm{A}}$ & $1.64 \pm 0.02^{\mathrm{B}}$ \\
\hline 7 & Dodecanol & $1.25 \pm 0.01^{\mathrm{a}}$ & $1.75 \pm 0.03^{\mathrm{b}}$ & $1.63 \pm 0.03^{\mathrm{c}}$ & $1.64 \pm 0.03^{\mathrm{A}}$ & $1.66 \pm 0.02^{\mathrm{A}}$ & $1.64 \pm 0.01^{\mathrm{A}}$ \\
\hline 9 & Tridecanol & $1.27 \pm 0.01^{\mathrm{a}}$ & $1.93 \pm 0.05^{\mathrm{b}}$ & $1.66 \pm 0.04^{\mathrm{c}}$ & $1.72 \pm 0.01^{\mathrm{A}}$ & $1.78 \pm 0.02^{\mathrm{B}}$ & $1.69 \pm 0.02^{\mathrm{A}}$ \\
\hline 10 & Tetradecanol & $1.28 \pm 0.02^{\mathrm{a}}$ & $1.75 \pm 0.03^{\mathrm{b}}$ & $1.71 \pm 0.01^{\mathrm{c}}$ & $1.68 \pm 0.05^{\mathrm{A}}$ & $1.68 \pm 0.02^{\mathrm{A}}$ & $1.66 \pm 0.01^{\mathrm{A}}$ \\
\hline 15 & Hexadecanol & $2.29 \pm 0.01^{\mathrm{a}}$ & $3.10 \pm 0.19^{\mathrm{b}}$ & $3.25 \pm 0.09^{\mathrm{b}}$ & $3.23 \pm 0.25^{\mathrm{A}}$ & $2.97 \pm 0.03^{\mathrm{A}}$ & $2.63 \pm 0.03^{\mathrm{B}}$ \\
\hline 24 & Octadece-9-nol ${ }^{1}$ & $3.19 \pm 0.06^{\mathrm{a}}$ & $4.26 \pm 0.26^{\mathrm{b}}$ & $4.62 \pm 0.12^{\mathrm{c}}$ & $6.42 \pm 0.38^{\mathrm{A}}$ & $4.06 \pm 0.07^{\mathrm{B}}$ & $3.67 \pm 0.04^{\mathrm{B}}$ \\
\hline 26 & Octadecanol & $1.95 \pm 0.03^{\mathrm{a}}$ & $2.58 \pm 0.11^{\mathrm{b}}$ & $2.76 \pm 0.02^{\mathrm{c}}$ & $2.60 \pm 0.17^{\mathrm{A}}$ & $2.52 \pm 0.03^{\mathrm{AB}}$ & $2.37 \pm 0.03^{\mathrm{B}}$ \\
\hline 28 & 3,7,11,15-Tetramethyl-2-hexadecen-1-ol & $3.19 \pm 0.09^{\mathrm{a}}$ & $6.45 \pm 0.60^{\mathrm{b}}$ & $5.80 \pm 0.30^{\mathrm{b}}$ & $5.65 \pm 0.08^{\mathrm{A}}$ & $6.20 \pm 0.04^{\mathrm{B}}$ & $5.50 \pm 0.04^{\mathrm{C}}$ \\
\hline 37 & Eicosanol & $1.28 \pm 0.01^{\mathrm{a}}$ & $1.69 \pm 0.02^{\mathrm{b}}$ & $1.66 \pm 0.03^{\mathrm{b}}$ & n.d & n.d & $1.66 \pm 0.01^{\mathrm{b}}$ \\
\hline
\end{tabular}


Table 4 (continued)

\begin{tabular}{|c|c|c|c|c|c|c|c|}
\hline \multirow[t]{2}{*}{ No } & \multirow[t]{2}{*}{ Identified compounds } & \multicolumn{3}{|c|}{ Hemiselmis cf. andersenii } & \multicolumn{3}{|l|}{ Pavlova pinguis } \\
\hline & & Low & Medium & High & Low & Medium & High \\
\hline 44 & Docosanol & $1.25 \pm 0.01^{\mathrm{a}}$ & $1.66 \pm 0.02^{\mathrm{b}}$ & $1.64 \pm 0.03^{b}$ & $1.63 \pm 0.05^{\mathrm{A}}$ & $1.65 \pm 0.02^{\mathrm{A}}$ & $1.64 \pm 0.01^{\mathrm{A}}$ \\
\hline 56 & Octacosanol & $1.41 \pm 0.03^{\mathrm{a}}$ & $1.86 \pm 0.05^{\mathrm{b}}$ & $1.93 \pm 0.03^{b}$ & $1.88 \pm 0.06^{\mathrm{A}}$ & $1.92 \pm 0.04^{\mathrm{A}}$ & $1.85 \pm 0.01^{\mathrm{A}}$ \\
\hline 66 & Octacosane-1,3-diol & $1.27 \pm 0.02^{\mathrm{a}}$ & $1.70 \pm 0.02^{\mathrm{b}}$ & $1.71 \pm 0.02^{\mathrm{b}}$ & n.d & n.d & n.d \\
\hline 68 & Tricosanol & $1.35 \pm 0.04^{\mathrm{a}}$ & $1.80 \pm 0.04^{\mathrm{b}}$ & $1.84 \pm 0.04^{\mathrm{b}}$ & $1.80 \pm 0.04^{\mathrm{A}}$ & $1.83 \pm 0.04^{\mathrm{A}}$ & $1.78 \pm 0.01^{\mathrm{A}}$ \\
\hline \multirow[t]{2}{*}{74} & Dotriacontanol & $1.27 \pm 0.01^{\mathrm{a}}$ & $1.69 \pm 0.01^{\mathrm{b}}$ & $1.67 \pm 0.03^{b}$ & $1.65 \pm 0.04^{\mathrm{A}}$ & $1.68 \pm 0.02^{\mathrm{A}}$ & $1.65 \pm 0.02^{\mathrm{A}}$ \\
\hline & Sterols & $1.83 \pm 0.07^{a}$ & $3.14 \pm 0.36^{b}$ & $3.31 \pm 0.10^{b}$ & $13.12 \pm 0.45^{A}$ & $16.96 \pm 0.97^{B}$ & $14.40 \pm 0.94^{A}$ \\
\hline 54 & 22-Stigmasten-3-one & n.d & n.d & n.d & $0.28 \pm 0.01^{\mathrm{A}}$ & $0.30 \pm 0.01^{\mathrm{AB}}$ & $0.31 \pm 0.01^{\mathrm{B}}$ \\
\hline 57 & $24 \beta$-Methylcholesta-5,22E-dien-3 $\beta$-ol & $0.73 \pm 0.01^{\mathrm{a}}$ & $1.67 \pm 0.25^{\mathrm{b}}$ & $1.60 \pm 0.03^{\mathrm{b}}$ & n.d & n.d & n.d \\
\hline 58 & $24 \alpha$-Methylcholest-5-en-3 $\beta$-ol & $0.24 \pm 0.01^{\mathrm{a}}$ & $0.31 \pm 0.02^{\mathrm{b}}$ & $0.33 \pm 0.02^{\mathrm{b}}$ & $0.61 \pm 0.00^{\mathrm{A}}$ & $0.74 \pm 0.03^{\mathrm{B}}$ & $0.68 \pm 0.07^{\mathrm{AB}}$ \\
\hline 60 & $24 \beta$-Ethylcholesta-5,22E-dien- $3 \beta$-ol & n.d & n.d & n.d & $0.33 \pm 0.01^{\mathrm{A}}$ & $0.35 \pm 0.01^{\mathrm{A}}$ & $0.37 \pm 0.05^{\mathrm{A}}$ \\
\hline 61 & $24 \alpha$-Ethylcholesta-5,22E-dien-3 $\beta$-ol & n.d & n.d & n.d & $4.22 \pm 0.18^{\mathrm{A}}$ & $6.64 \pm 0.46^{\mathrm{B}}$ & $5.45 \pm 0.38^{\mathrm{C}}$ \\
\hline 62 & 24 -Ethyl- $\delta(22)$-coprostenol & n.d & n.d & n.d & $0.53 \pm 0.02^{\mathrm{A}}$ & $0.71 \pm 0.08^{\mathrm{B}}$ & $0.62 \pm 0.06^{\mathrm{AB}}$ \\
\hline 63 & $24 \alpha$-Ethylcholest-5-en-3 $\beta$-ol & $0.62 \pm 0.07^{\mathrm{a}}$ & $0.83 \pm 0.08^{\mathrm{b}}$ & $1.05 \pm 0.05^{\mathrm{c}}$ & $1.32 \pm 0.05^{\mathrm{A}}$ & $1.36 \pm 0.07^{\mathrm{A}}$ & $1.16 \pm 0.09^{\mathrm{B}}$ \\
\hline 64 & Stigmasta-3,5-dien-7-one & $0.24 \pm 0.01^{\mathrm{a}}$ & $0.33 \pm 0.02^{\mathrm{b}}$ & $0.34 \pm 0.02^{\mathrm{b}}$ & $0.41 \pm 0.02^{\mathrm{A}}$ & $0.40 \pm 0.03^{\mathrm{A}}$ & $0.37 \pm 0.02^{\mathrm{A}}$ \\
\hline 65 & $4 \alpha, 24$-Dimethyl- $5 \alpha$-cholestan- $3 \beta$-ol & n.d & n.d & n.d & $0.83 \pm 0.03^{\mathrm{AB}}$ & $0.92 \pm 0.07^{\mathrm{A}}$ & $0.76 \pm 0.05^{\mathrm{B}}$ \\
\hline 67 & Unidentified sterol & n.d & n.d & n.d & $1.17 \pm 0.04^{\mathrm{A}}$ & $1.65 \pm 0.08^{\mathrm{B}}$ & $1.29 \pm 0.05^{\mathrm{A}}$ \\
\hline 69 & $\begin{array}{l}4 \alpha \text {-methyl,24-ethyl-5 } \alpha \text {-cholest-22E-en- } \\
3 \beta \text {-ol }\end{array}$ & n.d & n.d & n.d & $0.78 \pm 0.03^{\mathrm{A}}$ & $0.79 \pm 0.03^{\mathrm{A}}$ & $0.66 \pm 0.04^{\mathrm{B}}$ \\
\hline 70 & $4 \alpha$-methyl,24-ethyl-5 $\alpha$-cholestan-3-ol & n.d & n.d & n.d & $0.39 \pm 0.01^{\mathrm{A}}$ & $0.44 \pm 0.02^{\mathrm{B}}$ & $0.41 \pm 0.00^{\mathrm{A}}$ \\
\hline 72 & $\begin{array}{l}4 \alpha, 24 \beta \text {-dimethyl-5 } \alpha \text {-cholestan- } 3 \beta, 4 \beta \text { - } \\
\text { diol } *\end{array}$ & n.d & n.d & n.d & $0.42 \pm 0.01^{\mathrm{A}}$ & $0.48 \pm 0.02^{\mathrm{B}}$ & $0.42 \pm 0.01^{\mathrm{A}}$ \\
\hline 73 & Unidentified Sterol & n.d & n.d & n.d & $1.02 \pm 0.21^{\mathrm{A}}$ & $1.01 \pm 0.07^{\mathrm{A}}$ & $1.05 \pm 0.12^{\mathrm{A}}$ \\
\hline \multirow[t]{2}{*}{75} & 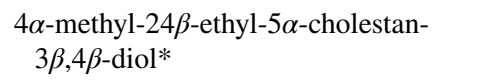 & n.d & n.d & n.d & $0.80 \pm 0.04^{\mathrm{A}}$ & $1.16 \pm 0.07^{\mathrm{B}}$ & $1.02 \pm 0.01^{\mathrm{C}}$ \\
\hline & Monoglycerides & $0.10 \pm 0.01^{a}$ & $0.23 \pm 0.05^{b}$ & $0.31 \pm 0.09^{b}$ & $0.10 \pm 0.01^{A}$ & $0.13 \pm 0.02^{A}$ & $0.11 \pm 0.02^{A}$ \\
\hline 46 & 2,3-Dihydroxypropyl palmitate & $0.03 \pm 0.01^{\mathrm{a}}$ & $0.03 \pm 0.01^{\mathrm{a}}$ & $0.06 \pm 0.01^{\mathrm{b}}$ & $0.05 \pm 0.00^{\mathrm{A}}$ & $0.06 \pm 0.01^{\mathrm{A}}$ & $0.05 \pm 0.01^{\mathrm{A}}$ \\
\hline 48 & 3-Octadecoxypropane-1,2-diol & $0.05 \pm 0.01^{\mathrm{a}}$ & $0.16 \pm 0.04^{\mathrm{b}}$ & $0.22 \pm 0.08^{\mathrm{b}}$ & $0.03 \pm 0.00^{\mathrm{A}}$ & $0.04 \pm 0.01^{\mathrm{B}}$ & $0.03 \pm 0.00^{\mathrm{AB}}$ \\
\hline \multirow[t]{2}{*}{51} & 2,3-Dihydroxypropyl stearate & $0.02 \pm 0.00^{\mathrm{a}}$ & $0.04 \pm 0.01^{\mathrm{b}}$ & $0.03 \pm 0.01^{\mathrm{ab}}$ & $0.02 \pm 0.01^{\mathrm{AB}}$ & $0.03 \pm 0.01^{\mathrm{A}}$ & $0.02 \pm 0.00^{\mathrm{B}}$ \\
\hline & Others & $0.32 \pm 0.01^{a}$ & $0.34 \pm 0.11^{a}$ & $0.51 \pm 0.09^{b}$ & $1.37 \pm 0.14^{A}$ & $1.25 \pm 0.18^{A}$ & $0.97 \pm 0.05^{B}$ \\
\hline 5 & 2,6-bis(1,1-Dimethylethyl)phenol & $0.02 \pm 0.00^{\mathrm{a}}$ & $0.12 \pm 0.04^{\mathrm{b}}$ & $0.04 \pm 0.01^{\mathrm{a}}$ & $0.31 \pm 0.01^{\mathrm{A}}$ & $0.14 \pm 0.02^{\mathrm{B}}$ & $0.11 \pm 0.01^{\mathrm{B}}$ \\
\hline 13 & Rhamnose & $0.30 \pm 0.00^{\mathrm{a}}$ & n.d & $0.40 \pm 0.01^{\mathrm{b}}$ & $0.41 \pm 0.01^{\mathrm{A}}$ & $0.41 \pm 0.01^{\mathrm{A}}$ & $0.41 \pm 0.01^{\mathrm{A}}$ \\
\hline 35 & Dehydroabietic acid & n.d & $0.22 \pm 0.08^{\mathrm{a}}$ & $0.19 \pm 0.01^{\mathrm{a}}$ & $0.76 \pm 0.06^{\mathrm{A}}$ & $0.70 \pm 0.15^{\mathrm{A}}$ & $0.41 \pm 0.05^{\mathrm{B}}$ \\
\hline \multirow[t]{2}{*}{55} & $\alpha$-Tocopherol & n.d & n.d & n.d & $0.03 \pm 0.01^{\mathrm{A}}$ & n.d & $0.04 \pm 0.01^{\mathrm{A}}$ \\
\hline & Total & $70.18 \pm 1.07^{a}$ & $116.84 \pm 6.84^{b}$ & $111.89 \pm 3.81^{b}$ & $180.59 \pm 4.69^{A}$ & $183.79 \pm 4.73^{A}$ & $165.85 \pm 2.07^{B}$ \\
\hline
\end{tabular}

Values (means \pm SD of four replicates) in the same row, not sharing a common superscript, are significantly different $(p<0.05)$. Differences among treatments assessed by one-way ANOVA followed by Tukey post-hoc analysis are represented by superscript lowercase letters for $H$. cf. andersenii, and by superscript uppercase letters for P. pinguis. All the compounds containing hydroxyl and/or carboxyl groups are identified as the correspondent trimethylsilyl (TMS) derivatives. ${ }^{1}$ Contains cis and trans isomers. $n . d$. ., non detected. * identified as mono-TMS ether

(41\%) — which targets the acyl bonds of complex lipidswas verified at LP conditions. This could indicate that at LP conditions both $H$. cf. andersenii and $P$. pinguis tend to accumulate neutral lipids such as triacylglycerols. Moreover, campestenyl and campesteryl glycosides were only detected for $P$. pinguis samples (Table 3), and the greatest amounts were found at LP conditions, where the highest monosaccharide levels (180.27 $\mathrm{mg} \mathrm{g}^{-1} \mathrm{dw}$ ) were observed. As with phospholipids, glycosyl sterols are amphiphilic molecules which can be used by microalgal cells to maintain the organization and fluidity of membranes (Fernandes et al. 2021). Therefore, the previous observations seem to indicate that both microalgae responded to LP conditions by synthesizing non-phosphorus-containing lipids to offset the degradation of phospholipids.

As with nucleic acids, phospholipids are the major phosphorus reservoirs within microalgal cell (Mooy et al. 2009). Previous studies have reported that phosphorus scarcity induced lipid remodeling including the replacement of membrane phospholipids by non-phosphorus-containing lipids 
Fig. 4 Variations in fatty acids nutritional ratios for Hemiselmis cf. andersenii (a) and Pavlova pinguis (b) as a response to phosphorus-induced changes (LP, low phosphorus; MP, medium phosphorus; HP, high phosphorus supplementations), before $(\mathrm{BH})$ and after $(\mathrm{AH})$ alkaline hydrolysis. Values from the same nutritional ratio sharing common symbols (* before hydrolysis, and ** after hydrolysis) are not significantly different $(p>0.05)$ among treatments
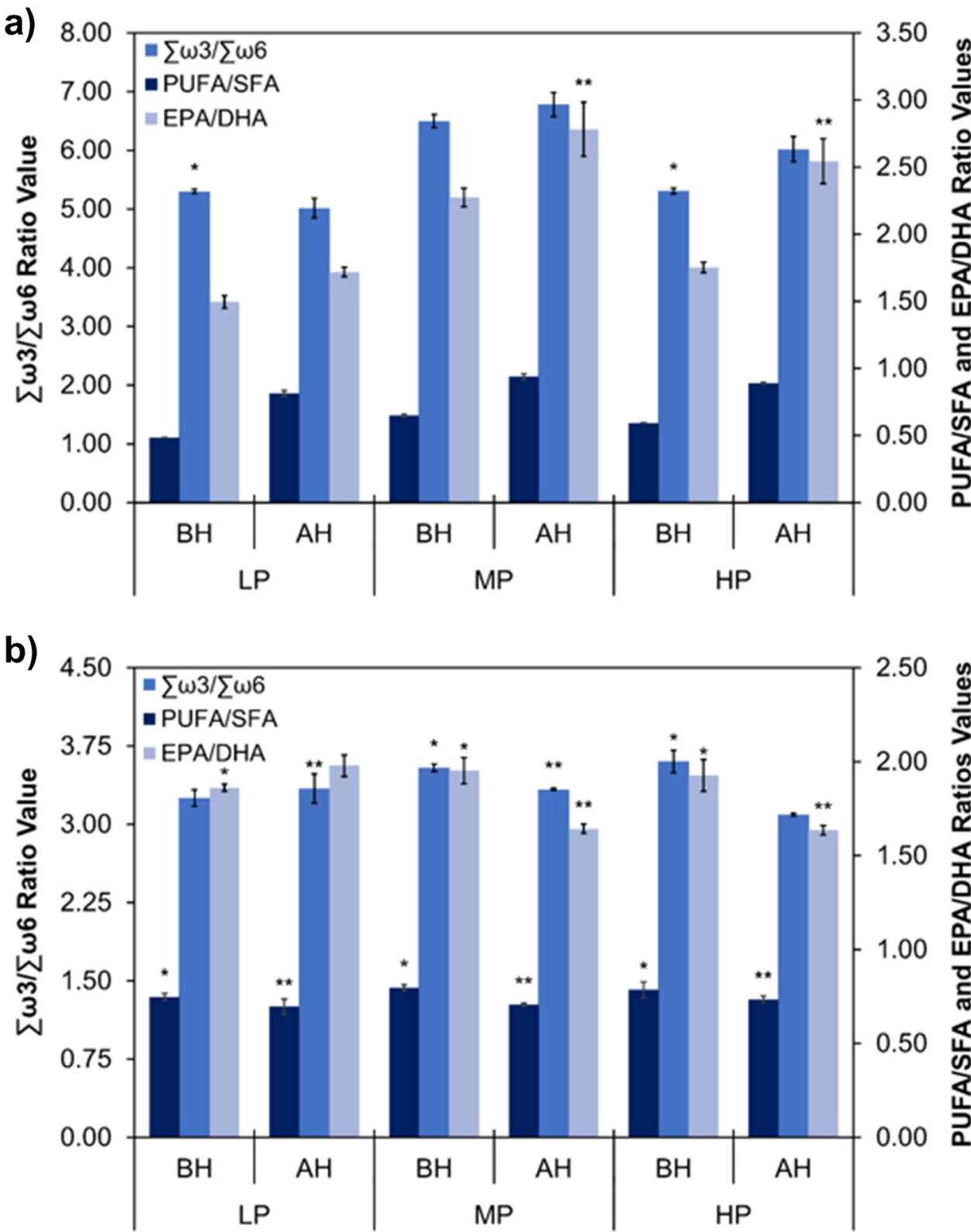

such as triacylglycerols (Khozin-Goldberg and Cohen 2006), glycolipids (Liang et al. 2013), and sulpholipids (Liang et al. 2013). Furthermore, Mooy et al. (2009) suggested that phospholipid substitutions are fundamental biochemical mechanisms that allow microalgae to maintain growth and photosynthesis in environments where phosphorus is scarce.

\section{Multivariate analysis of lipid composition}

Compositional changes were verified for both microalgae submitted to LP, MP, and HP conditions. Thus, to summarize the overall changes in metabolites, a principal component analysis (PCA) was performed to lipid data. Through this analysis, it is possible to visualize a clear separation between the lipidomic analysis for $H$. cf. andersenii (Fig. 5a) and $P$. pinguis (Fig. 5c) LP, MP, and HP cultures before and after alkaline hydrolysis. Principal component 1 (PC1) explained $67.4 \%$ of variance for $H$. cf. andersenii samples and 55.2\% of variance for $P$. pinguis. This component clearly separates samples before (left quadrant) and after alkaline hydrolysis (right quadrant) in both microalgae studied. Principal component 2 (PC2) explained $15.2 \%$ of variance for $H$. cf. andersenii and $16.6 \%$ for $P$. pinguis and separated samples according to the phosphorus-induced changes. For $H$. cf. andersenii samples, microalgae grown in LP conditions are 
distributed in the upper quadrant, while MP and HP conditions are both in the down quadrant. An opposite distribution was verified for $P$ pinguis samples with samples at LP conditions being distributed in the down quadrant and the MP and HP treatments being observed at the upper quadrant.

Loadings plots allow visualizing which variables had more influence on sample differentiation. For $H$. cf. andersenii (Fig. 5b), samples within the loadings most related to MP and HP conditions before hydrolysis were $24 \beta$-methylcholesta-5,22E-dien-3 $\beta$-ol (brassicasterol; 57 ), $\alpha$-tocopherol (55), and C16:2w4 (19) fatty acid, while after hydrolysis phytol (28), and the main fatty acids, C14, essential fatty acids $(29,30)$, EPA (36), DHA (41), and C16:0 (23) were the greatest contributors for its distribution among PCA scores. The separation of LP cultures to MP and HP conditions was mostly due to monoglycerides (2,3-dihydroxy-2-propanyl myristate (39), 1,3-dihydroxypropyl myristate (38), 2,3-dihidroxy-2-propanyl palmitate (46), and 1,3-dihydroxypropyl palmitate (45)) and the main aliphatic alcohols hexadecanol (15) and octadecene-9-ol (24). After alkaline hydrolysis, the monounsaturated fatty acids and long-chain aliphatic alcohols were among the loadings that contributed to its separation.

Cholesterol-lowering and anti-aging activities have been described for brassicasterol derived from cryptophytes (Abidizadegan et al. 2021). To produce this sterol by $H$. cf. andersenii, P-replete conditions such as those in MP and HP conditions should be used. ALA and 9,12-octadecadi-

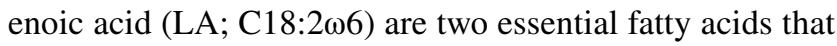
are needed for normal growth and development of animals; however, they lack the ability to synthesize these precursors of PUFA (DHA and EPA), which, in turn, makes its dietary intake mandatory. Thus, the rich composition of $H$. cf. andersenii saponifiable lipids in essential fatty acids (ALA and LA), and long-chain PUFA (EPA and DHA) at MP and HP cultures, reinforces that P-replete conditions are good to boost $H$. cf. andersenii composition in health-promoting lipids.

For P. pinguis (Fig. 5d) at LP conditions, steryl glycosides (76, 78), $\alpha$-tocopherol (55), and four of the seven monoglycerides (2,3-dihidroxy-2-propanyl palmitate (46), 1,3-dihydroxypropyl palmitate (45), 2,3-dihidroxy-2-propanyl stearate (51), and 1,3-dihydroxypropyl stearate (50)) detected for $P$. pinguis were among the loadings that contributed to the separation of this set from the remaining. MP and HP conditions were more related to most sterols, EPA, octadecanol, and tetradecanol. After hydrolysis, $P$. pinguis at LP conditions were mainly related to saturated and unsaturated $\mathrm{C} 18$ fatty acids, hexadecanoic acid, and clupadonic acid, while MP and HP conditions exhibited preference towards longchain alcohols, phytol, DHA, unsaturated $\mathrm{C} 16$ fatty acids.

$24 \alpha$-Ethylcholesta-5,22E-dien-3 $\beta$-ol (stigmasterol; 61), $24 \alpha$-methylcholest-5-en-3 $\beta$-ol (campesterol; 58), and
$24 \alpha$-ethylcholest-5-en-3 $\beta$-ol (sitosterol; 63) have attracted commercial interest in the pharmaceutical, nutraceutical, and functional food industries (Randhir et al. 2020). These 4-desmethyl sterols have well-established cholesterol-lowering properties, as well as other bioactivities such as anticancer and anti-inflammatory (Luo et al. 2015). All these three sterols are produced by $P$. pinguis and presented their highest amounts at MP and HP conditions (Table 3).

Within lipid-soluble compounds, tocopherols are often referred to as an underexploited resource from microalgae (Carballo-Cárdenas et al. 2003; Mudimu et al. 2017). $\alpha$-Tocopherol is especially known for its antioxidant activity and health properties such as prevention of light-induced pathologies, degenerative disorders, cardiovascular diseases, and cancer (Carballo-Cárdenas et al. 2003). In the industrial field, this compound is used in the preservation of food, in cosmetics, and as an additive in animal field. Thus, for $\alpha$-tocopherol production, the best conditions in the present study were MP and HP conditions before hydrolysis for $H$. cf. andersenii, and LP conditions for P. pinguis. Mudimu et al. (2017) performed a screen of microalgae strains for $\alpha$-tocopherol content and studied the influence of nitrate reduction on $\alpha$-tocopherol production. In this study, $\alpha$-tocopherol content in microalgae ranged between 20.52 and $1445.66 \mu \mathrm{g} \mathrm{g}^{-1} \mathrm{dw}$, and nutrient reduction leads to an increase in $\alpha$-tocopherol content. In this study, $P$. pinguis presented the highest amount of this molecule accounting $170 \mu \mathrm{g} \mathrm{g}^{-1} \mathrm{dw}$ at LP conditions.

For $H$. cf. andersenii, hierarchical cluster analysis (Fig. 6a) showed the same trends displayed by principal component analysis, with LP treatments showing the deepest lipid remodeling when compared to MP and HP conditions before and after alkaline hydrolysis. In P. pinguis (Fig. 6b) after hydrolysis, LP and MP conditions are closely related according to hierarchical cluster analysis. This trend is different from that displayed by PCA. This may be derived from $P$. pinguis cultured at LP and MP conditions which presented the lowest content of unsaponifiable material, with the greatest increase of total identified compounds with alkaline hydrolysis being verified at LP conditions $(31 \%)$.

\section{Conclusions}

This work provided novel insights on the response of marine microalgae to phosphorus-induced changes and their potential as a tool for optimizing high-value lipid production. Increasing initial phosphorus concentrations enhanced Pavlova pinguis and Hemiselmis cf. andersenii biomass productivities, making these conditions suitable for efficient high-value compounds production. Monosaccharide 


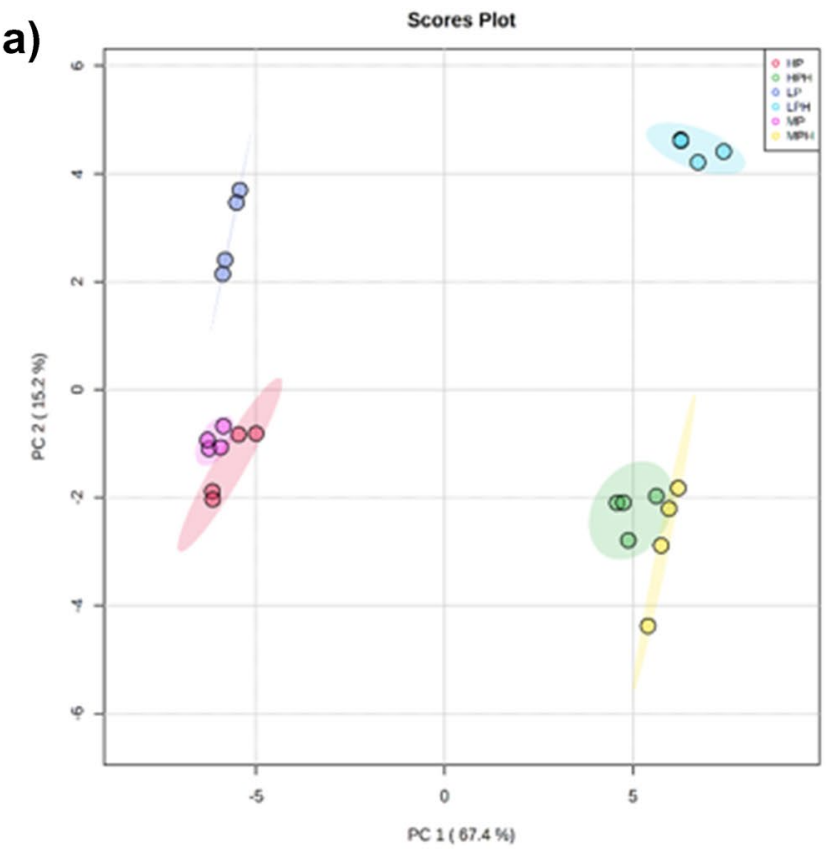

b)

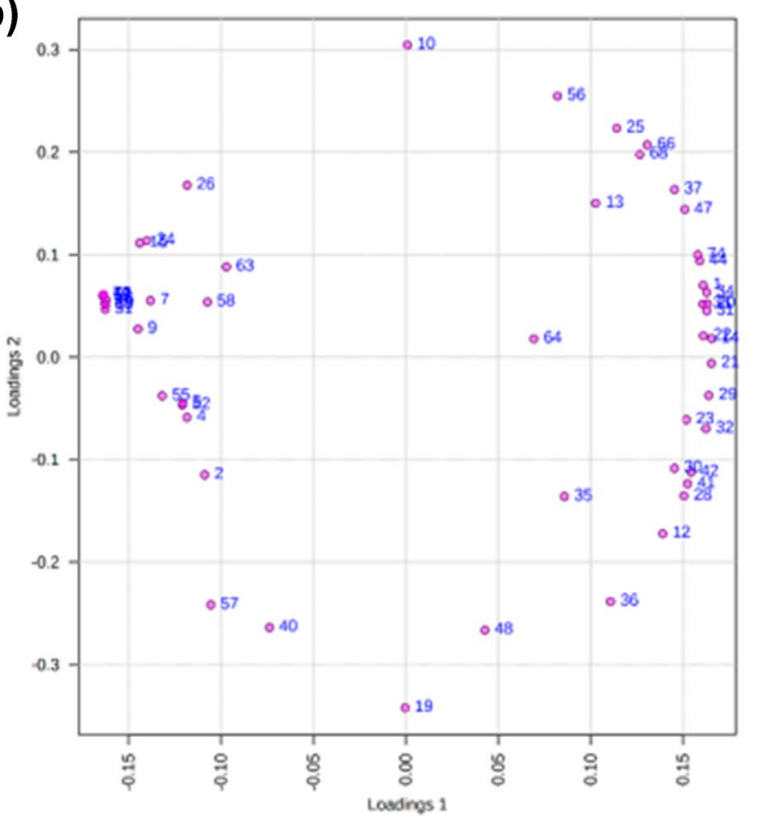

Fig. 5 Principal component analysis performed for the microalgae studied: scores plot of Hemiselmis cf. andersenii (a), loadings plot of Hemiselmis cf. andersenii (b), scores plot of Pavlova pinguis (c), loading plot of Pavlova pinguis (d). HP, MP, and HP stand for $H$. cf. andersenii and $P$. pinguis grown under low, medium, and high phos-

data, along with lipid/monosaccharide ratio, indicates that $P$. pinguis responded to low phosphorus conditions by synthesizing a $\beta$-1,3-glucan, while $H$. cf. andersenii seemed to divert its carbon to lipid production regardless of the treatment applied. In $P$. pinguis, the $\mathrm{Car} / \mathrm{Chl} a$ could be a simple indicator for determining carbon allocation among carbon-rich pools. In $H$. cf. andersenii, the co-production of
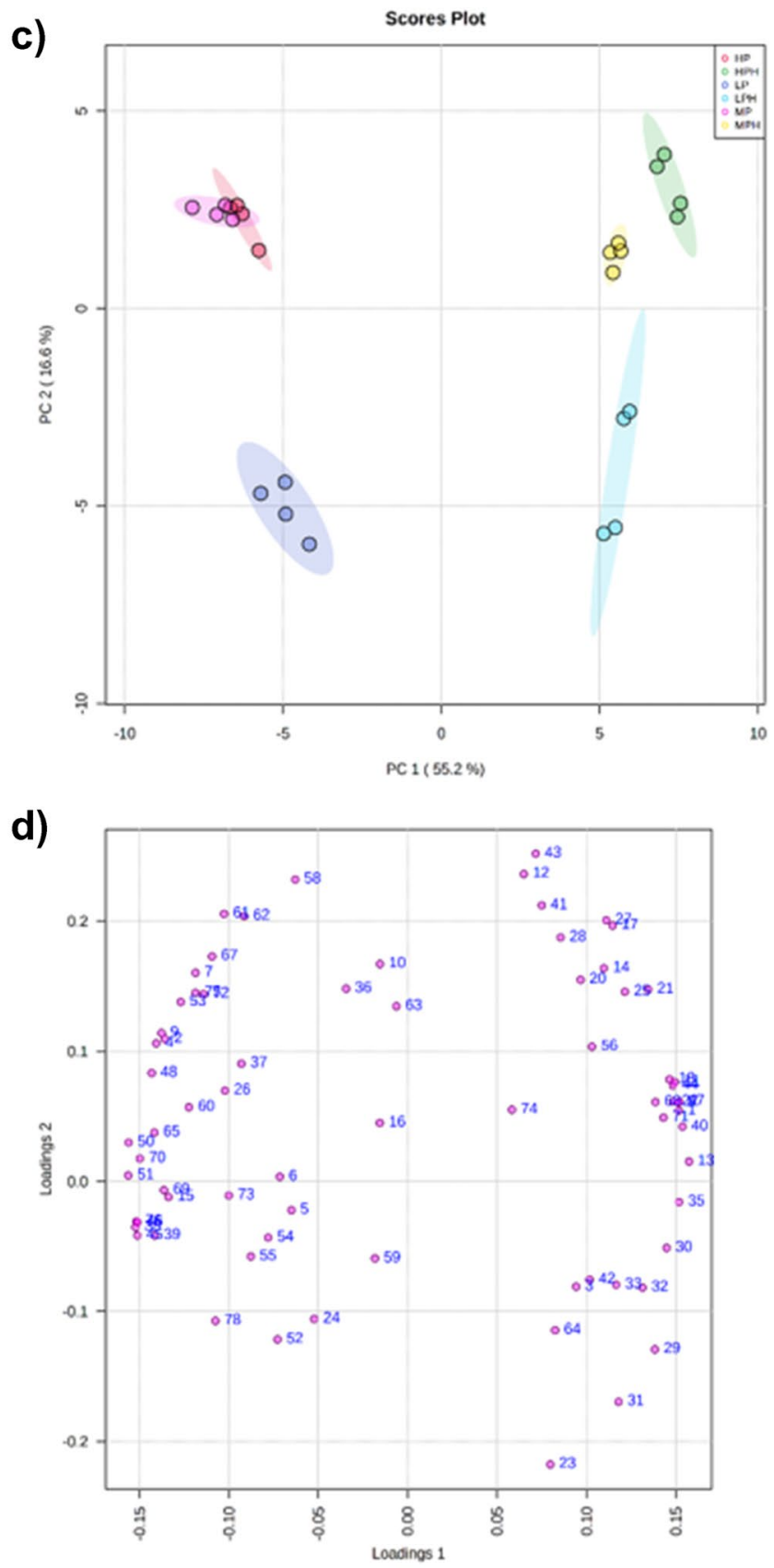

phorus supplementations, respectively, and analyzed before hydrolysis. LPH, MPH, and HPH stand for $H$. cf. andersenii and P. pinguis grown under low, medium, and high phosphorus supplementations, respectively, and analyzed after hydrolysis. Loading's descriptions can be seen in Tables 1 and 2

carotenoids and lipids against phosphorus-induced changes constitutes a major advantage for microalgae-based industries. Phosphorus-induced changes showed to be an effective tool for inducing lipid remodeling in $P$. pinguis and $H$. cf. andersenii, with P-replete conditions being the most effective to induce the accumulation of high-value lipids in both microalgae. 


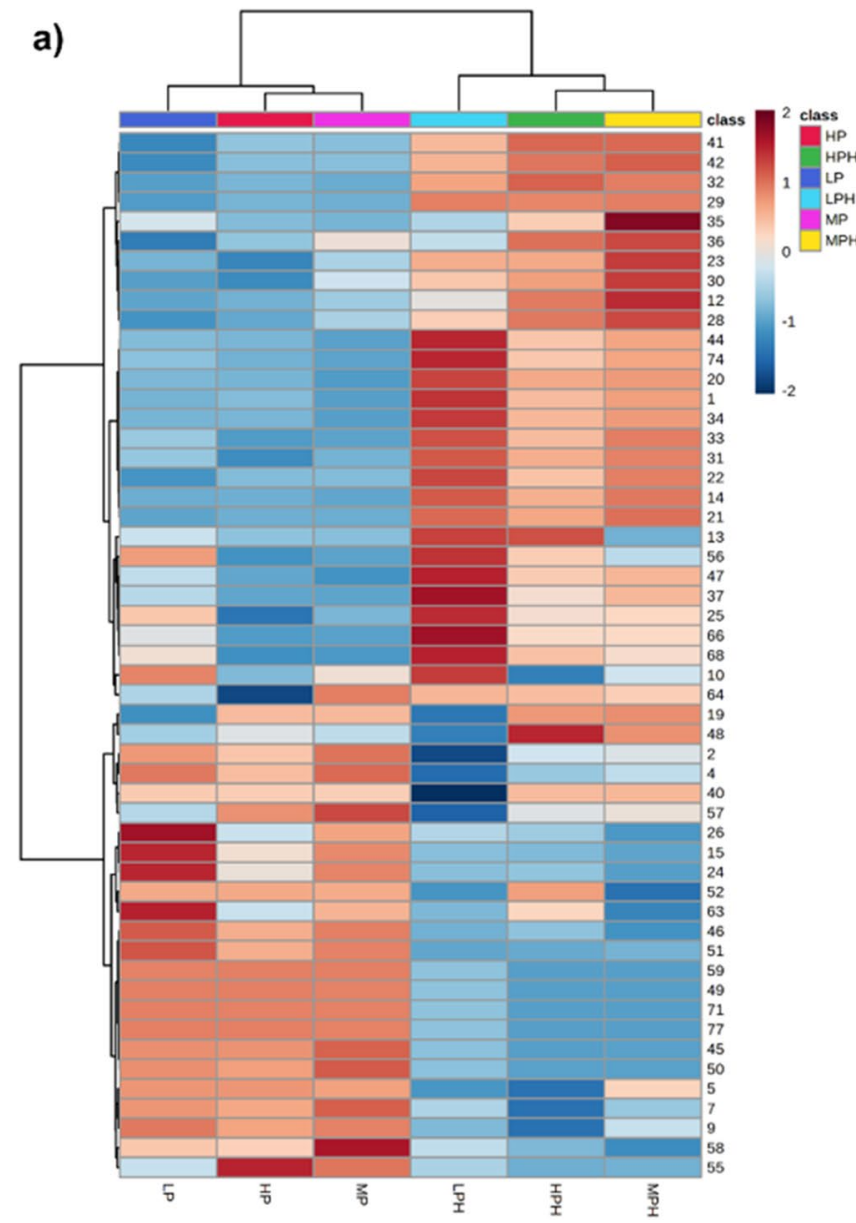

Fig. 6 Hierarchical clustering analysis heat maps based on Euclidean clustering distance and the ward clustering method, $n=4$ replicates, for Hemiselmis cf. andersenii (a) and Pavlova pinguis (b) grown under different phosphorus supplementations. Feature descriptions can be seen in Tables 3 and 4. The heat maps reflect the relative levels of metabolites among different treatment groups, the color scheme is associated with the elevation and reduction in metabolite level

Supplementary Information The online version contains supplementary material available at https://doi.org/10.1007/s10811-021-02662-2.

Author contribution T.F. and N.C. contributed to the conception and design of the study. T.F. executed the experiment, analyzed and interpreted the data, and wrote the manuscript. N.C. made possible the execution of the experiment by providing administrative and financial support, supervising the experiment, and making critical revisions regarding important intellectual content of the manuscript. All authors read and approved the final manuscript.

Acknowledgments This research was supported by Foundation for Science and Technology-FCT, through UIDB/04423/2020 and UIDP/04423/2020, and by the European Territorial Cooperation Programme PCT- MAC 2014-2020, through the project REBECACCT (MAC/1.1.B/269). Tomásia Fernandes was financially supported by a doctoral grant from Regional Agency for Development of Research, Technology, and Innovation of Madeira-ARDITI, Project M1420-09-5369-FSE-000002.

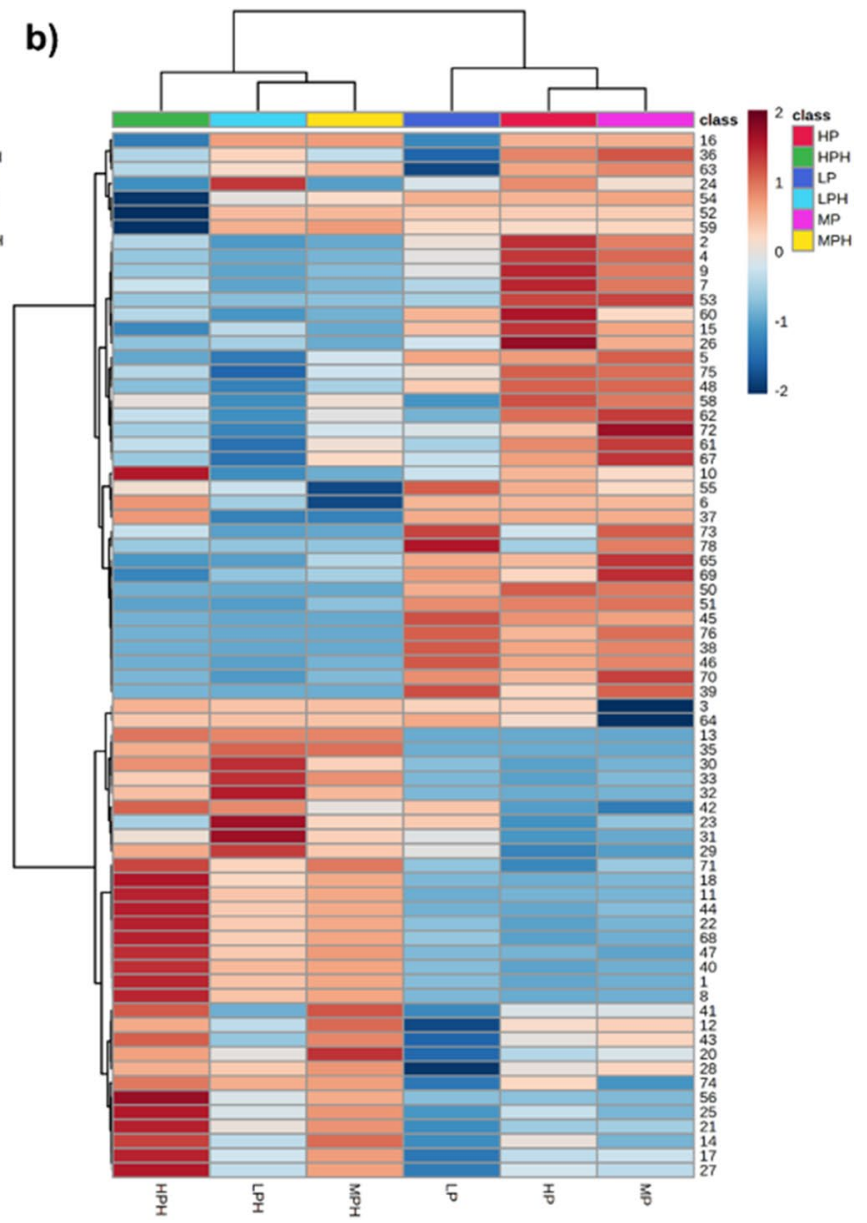

through treatments: dark blue, lowest; dark red, highest. HP, MP, and HP stand for $H$. cf. andersenii and $P$. pinguis grown under low, medium, and high phosphorus supplementations, respectively, and analyzed before hydrolysis. LPH, MPH, and HPH stands for $H$. cf. andersenii and $P$. pinguis grown under low, medium, and high phosphorus supplementations, respectively, and analyzed after hydrolysis

Data availability All data generated or analyzed during this study are included in this published article.

\section{Declarations}

Conflict of interest The authors declare no competing interests.

\section{References}

Abidizadegan M, Peltomaa E, Blomster J (2021) The potential of cryptophyte algae in biomedical and pharmaceutical applications. Front Pharmacol 11:618836

Akgül R, Akgül F, Tüney Kızılkaya İ (2021) Effects of different phosphorus concentrations on growth and biochemical composition of 
Desmodesmus communis (E.Hegewald) E.Hegewald. Prep Biochem Biotechnol 51:705-713

Alipanah L, Winge P, Rohloff J, Najafi J, Brembu T, Bones AM (2018) Molecular adaptations to phosphorus deprivation and comparison with nitrogen deprivation responses in the diatom Phaeodactylum tricornutum. PLoS One 13:e0193335

Barsanti L, Gualtieri P (2006) Summaries of the ten algal divisions. In: Barsanti L, Gualtieri P (eds) Algae: anatomy, biochemistry, and biotechnology. CRC Press, Boca Raton, pp 1-35

Becker EW (1994) Microalgae: biotechnology and microbiology. Cambridge University Press, Cambridge

Blakeney AB, Harris PJ, Henry RJ, Stone BA (1983) A simple and rapid preparation of alditol acetates for monosaccharide analysis. Carbohydr Res 113:291-299

Bligh EG, Dyer WJ (1959) A rapid method of total lipid extraction and purification. Can J Biochem Physiol 37:911-917

Cagliari A, Margis R, Dos Santos MF, Turchetto-Zolet AC, Loss G, Margis-Pinheiro M (2011) Biosynthesis of triacylglycerols (TAGs) in plants and algae. Int J Plant Biol 2:40-52

Cañavate JP, Armada I, Hachero-Cruzado I (2017) Interspecific variability in phosphorus-induced lipid remodelling among marine eukaryotic phytoplankton. New Phytol 213:700-713

Carballo-Cárdenas EC, Tuan PM, Janssen M, Wijffels RH (2003) Vitamin E ( $\alpha$-tocopherol) production by the marine microalgae Dunaliella tertiolecta and Tetraselmis suecica in batch cultivation. Biomol Eng 20:139-147

Chen J, Wei D, Pohnert G (2017) Rapid estimation of astaxanthin and the carotenoid-to-chlorophyll ratio in the green microalga Chromochloris zofingiensis using flow cytometry. Mar Drugs 15:md15070231

Chen Y, Vaidyanathan S (2013) Simultaneous assay of pigments, carbohydrates, proteins and lipids in microalgae. Anal Chim Acta $776: 31-40$

Fernandes T, Cordeiro N (2020) Hemiselmis andersenii and Chlorella stigmatophora as new sources of high-value compounds: a lipidomic approach. J Phycol 56:1493-1504

Fernandes T, Fernandes I, Andrade CAP, Ferreira A, Cordeiro N (2017) Marine microalgae monosaccharide fluctuations as a stress response to nutrients inputs. Algal Res 24:340-346

Fernandes T, Fernandes I, Andrade CAP, Cordeiro N (2016) Marine microalgae growth and carbon partitioning as a function of nutrient availability. Bioresour Technol 214:541-547

Fernandes T, Ferreira A, Cordeiro N (2021) Comparative lipidomic analysis of Chlorella stigmatophora and Hemiselmis cf. andersenii in response to nitrogen-induced changes. Algal Res 58:102417

Fernandes T, Martel A, Cordeiro N (2020) Exploring Pavlova pinguis chemical diversity: a potentially novel source of high value compounds. Sci Rep 10:339

Fu W, Chaiboonchoe A, Khraiwesh B, Nelson DR, Al-Khairy D, Mystikou A, Alzahmi A, Salehi-Ashtiani K (2016) Algal cell factories: approaches, applications, and potentials. Mar Drugs $14: 225$

da Gorgônio CM, S, Aranda DAG, Couri S, (2013) Morphological and chemical aspects of Chlorella pyrenoidosa, Dunaliella tertiolecta, Isochrysis galbana and Tetraselmis gracilis microalgae. Nat Sci 05:783-791

Grobbelaar JU (2013) Inorganic algal nutrition. In: Richmond A, Hu Q (eds) Handbook of microalgal culture: applied phycology and biotechnology, 2nd edn. John Wiley \& Sons, NY, pp 123-133

Guillard RR, Ryther JH (1962) Studies of marine planktonic diatoms. I. Cyclotella nana Hustedt, and Detonula confervacea (Cleve) Gran. Can J Microbiol 8:229-239

Guillard RRL (1975) Culture of phytoplankton for feeding marine invertebrates. In: Smith WL, Chanley MH (eds) Culture of marine invertebrate animals. Springer, Boston, pp 29-60

Harwood JL (2019) Algae: critical sources of very long-chain polyunsaturated fatty acids. Biomolecules 9:708
Jo S-W, Hong JW, Do J-M, Na H, Kim J-J, Park S-I, Kim Y-S, Kim I-S, Yoon H-S (2020) Nitrogen deficiency-dependent abiotic stress enhances carotenoid production in indigenous green microalga Scenedesmus rubescens KNUA042, for use as a potential resource of high value products. Sustainability 12:5445

Khozin-Goldberg I, Cohen Z (2006) The effect of phosphate starvation on the lipid and fatty acid composition of the fresh water eustigmatophyte Monodus subterraneus. Phytochemistry 67:696-701

Khozin-Goldberg I, Iskandarov U, Cohen Z (2011) LC-PUFA from photosynthetic microalgae: occurrence, biosynthesis, and prospects in biotechnology. Appl Microbiol Biotechnol 91:905-915

Kokabi K, Gorelova O, Ismagulova T, Itkin M, Malitsky S, Boussiba S, Solovchenko A, Khozin-Goldberg I (2019) Metabolomic foundation for differential responses of lipid metabolism to nitrogen and phosphorus deprivation in an arachidonic acid-producing green microalga. Plant Sci 283:95-115

Le Goff M, Le Ferrec E, Mayer C, Mimouni V, Lagadic-Gossmann D, Schoefs D, Ulmann L (2019) Microalgal carotenoids and phytosterols regulate biochemical mechanisms involved in human health and disease prevention. Biochimie 167:106-118

Lee Y, Chen W, Shen H, Han D, Li Y, Jones HDT, Timlin JA, Hu Q (2013) Basic culturing and analytical measurement techniques. In: Richmond A, Hu Q (eds) Handbook of microalgal culture: applied phycology and biotechnology, 2nd edn. John Wiley \& Sons, NY, pp 37-68

Li Y, Han D, Yoon K, Zhu S, Sommerfeld M, Hu Q (2013). In: Richmond A, Hu Q (eds) Handbook of microalgal culture, Second Edn. John Wiley \& Sons, New York, pp 545-565

Liang K, Zhang Q, Gu M, Cong W (2013) Effect of phosphorus on lipid accumulation in freshwater microalga Chlorella sp. J Appl Phycol 25:311-318

López G, Yate C, Ramos FA, Cala MP, Restrepo S, Baena S (2019) Production of polyunsaturated fatty acids and lipids from autotrophic, mixotrophic and heterotrophic cultivation of Galdieria sp. strain USBA-GBX-832. Sci Rep 9:10791

Luo X, Su P, Zhang W (2015) Advances in microalgae-derived phytosterols for functional food and pharmaceutical applications. Mar Drugs 13:4231-4254

Markou G, Chatzipavlidis I, Georgakakis D (2012) Carbohydrates production and bio-flocculation characteristics in cultures of Arthrospira (Spirulina) platensis: improvements through phosphorus limitation process. Bioenergy Res 5:915-925

Van Mooy BAS, Fredricks HF, Pedler BE, Dyhrman ST, Karl DM, Koblížek M, Lomas MW, Mincer TJ, Moore LR, Moutin T, Rappé MS, Webb EA (2009) Phytoplankton in the ocean use non-phosphorus lipids in response to phosphorus scarcity. Nature 458:69-72

Mudimu O, Koopmann IK, Rybalka N, Fridl T, Schulz R, Bilger W (2017) Screening of microalgae and cyanobacteria strains for $\alpha$-tocopherol content at different growth phases and the influence of nitrate reduction on $\alpha$-tocopherol production. J Appl Phycol 29:2867-2875

Murakami H, Nobusawa T, Hori K, Shimojima M, Ohta H (2018) Betaine lipid is crucial for adapting to low temperature and phosphate deficiency in Nannochloropsis. Plant Physiol 177:181-193

Pang Z, Chong J, Zhou G, de Lima Morais DA, Chang L, Barrette M, Gauthier C, Jacques P-É, Li S, Xia J (2021) MetaboAnalyst 5.0: narrowing the gap between raw spectra and functional insights. Nucleic Acids Res 49:W388-W396

Patel A, Barrington S, Lefsrud M (2012) Microalgae for phosphorus removal and biomass production: a six species screen for dualpurpose organisms. GCB Bioenergy 4:485-495

Piepho M, Martin-Creuzburg D, Wacker A (2012) Phytoplankton sterol contents vary with temperature, phosphorus and silicate supply: a study on three freshwater species. Eur J Phycol 47:138-145 
Piepho M, Martin-Creuzburg D, Wacker A (2010) Simultaneous effects of light intensity and phosphorus supply on the sterol content of phytoplankton. PLoS ONE 5:e15828

Randhir A, Laird DW, Maker G, Trengove R, Moheimani NR (2020) Microalgae: a potential sustainable commercial source of sterols. Algal Res 46:101772

Reitan KI, Rainuzzo JR, Olsen Y (1994) Effect of nutrient limitation on fatty acid and lipid content of marine microalgae. J Phycol 30:972-979

Roopnarain A, Gray VM, Sym SD (2014) Phosphorus limitation and starvation effects on cell growth and lipid accumulation in Isochrysis galbana $\mathrm{U} 4$ for biodiesel production. Bioresour Technol 156:408-411

Saha SK, McHugh E, Hayes J, Moane S, Walsh D, Murray P (2013) Effect of various stress-regulatory factors on biomass and lipid production in microalga Haematococcus pluvialis. Bioresour Technol 128:118-124

Samiee-Zafarghandi R, Karimi-Sabet J, Abdoli MA, Karbassi A (2018) Increasing microalgal carbohydrate content for hydrothermal gasification purposes. Renew Energy 116:710-719

Santos SA, Vilela C, Freire CS, Abreu MH, Rocha SM, Silvestre AJ (2015) Chlorophyta and rhodophyta macroalgae: a source of health promoting phytochemicals. Food Chem 183:122-128

Sasso S, Pohnert G, Lohr M, Mittag M, Hertweck C (2012) Microalgae in the postgenomic era: A blooming reservoir for new natural products. FEMS Microbiol Rev 36:761-785

Satpati GG, Gorain PC, Pal R (2016) Efficacy of EDTA and phosphorous on biomass yield and total lipid accumulation in two green microalgae with special emphasis on neutral lipid detection by flow cytometry. Adv Biol 2016:8712470

Shang T, Liu L, Zhou J, Zhang M, Hu Q, Fang M, Wu Y, Yao P, Gong Z (2017) Protective effects of various ratios of DHA/EPA supplementation on high-fat diet-induced liver damage in mice. Lipids Health Dis 16:65

Shen PL, Wang HT, Pan YF, Meng YY, Wu PC, Xue S (2016) Identification of characteristic fatty acids to quantify triacylglycerols in microalgae. Front Plant Sci 7:162
Singh P, Kumari S, Guldhe A, Misra R, Rawat I, Bux F (2016) Trends and novel strategies for enhancing lipid accumulation and quality in microalgae. Renew Sustain Energy Rev 55:1-16

Siron R, Giusti G, Berland B (1989) Changes in the fatty acid composition of Phaeodactylum tricornutum and Dunaliella tertiolecta during growth and under phosphorus deficiency. Mar Ecol Prog Ser 55:95-100

Slocombe SP, Zhang Q, Ross M, Anderson A, Thomas NJ, Lapresa Á, Rad-Menéndez C, Campbell CN, Black KD, Stanley MS, Day JG (2015) Unlocking nature's treasure-chest: screening for oleaginous algae. Sci Rep 5:9844

Sun M, Yang Z, Wawrik B (2018) Metabolomic fingerprints of individual algal cells using the single-probe mass spectrometry technique. Front Plant Sci 9:571

Vieira MV, Pastrana LM, Fuciños P (2020) Microalgae encapsulation systems for food, pharmaceutical and cosmetics applications. Mar Drugs 18:md18120644

Wan C, Bai FW, Zhao XQ (2013) Effects of nitrogen concentration and media replacement on cell growth and lipid production of oleaginous marine microalga Nannochloropsis oceanica DUT01. Biochem Eng J 78:32-38

Xin L, Hong-ying H, Ke G, Ying-xue S (2010) Effects of different nitrogen and phosphorus concentrations on the growth, nutrient uptake, and lipid accumulation of a freshwater microalga Scenedesmus sp. Bioresour Technol 101:5494-5500

Yaakob MA, Mohamed RMSR, Al-Gheethi A, Aswathnarayana Gokare R, Ambati RR (2021) Influence of nitrogen and phosphorus on microalgal growth, biomass, lipid, and fatty acid production: an overview. Cells 10:393

Yang F, Xiang W, Li T, Long L (2018) Transcriptome analysis for phosphorus starvation-induced lipid accumulation in Scenedesmus sp. Sci Rep 8:16421

Publisher's note Springer Nature remains neutral with regard to jurisdictional claims in published maps and institutional affiliations. 